\title{
Regulatory Objectives and the Intensity of Unbundling in Electricity Markets*
}

\author{
Henrik Lindemann ${ }^{\varpi}$
}

\author{
Discussion Paper No. 544 \\ ISSN 0949-9962 \\ January 2015
}

\begin{abstract}
Despite the positive effect electricity grids separated from generation and supply by ownership are expected to have on the level of competition in the non-network activities, several EU member states still adhere to a solely legally unbundled transmission grid. This choice might be induced by regulators focusing on objectives other than the promotion of consumer interests: theoretically analyzing the decisions an authority takes on both the unbundling regime and the grid charge when it supervises a network monopolist providing a downstream Cournot duopoly with capacity, we find an agency pursuing consumer-oriented goals to always implement Ownership Unbundling. For a regulator acting in the interests of the industry or the government, though, results suggest the authority to be indifferent between Legal and Ownership Unbundling; minor potential drawbacks of a network separated by ownership for the agency or the companies might then tip the scales and cause the regulator to adhere to Legal Unbundling.
\end{abstract}

JEL-classification: D73, L12, L13, L42, L50, L51, L94

Keywords: $\quad$ Legal Unbundling, Ownership Unbundling, Regulatory Authorities, Regulatory Objectives

\footnotetext{
*I would like to thank Andreas Wagener, Georgios Katsenos and Tobias Lausen as well as participants of the 8th EEM International Conference in Zagreb, the 34th IAEE International Conference in Stockholm and Workshops on Public Economics in Paderborn and Dortmund for helpful suggestions and discussions.

${ }^{\bowtie}$ Leibniz University of Hannover, School of Economics and Management, Koenigsworther Platz 1, 30167 Hannover, Germany, e-mail: lindemann@sopo.uni-hannover.de.
} 


\section{Introduction}

In its endeavor to create a single internal energy market, the European Union has gradually increased the degree of unbundling vertically integrated electricity utilities within member states had to realize over the years. The growing separation of monopolistic transmission and distribution grids from (potentially) competitive generation, wholesale and retail operations was intended to eliminate anti-competitive practices integrated companies were suspected to use to undermine the development and the functioning of the market: discriminations in the network access or cross-subsidies, for example, hamper the utility's competitors in power production and supply and might even completely deter them from providing their services; if, on the contrary, the network activities' interests in generation and retail profits are removed due to unbundling, competition can thrive and benefit consumers (European Commission, 2001, 2004; European Union, 2003).

The positive welfare effects associated with fully competitive markets should hence induce governments or authorities in charge of regulation to seek the complete elimination of discrimination incentives potentially persisting when utilities are not entirely unbundled: a thorough separation of the monopolistic and continuously regulated grid activities from generation and supply by means of a mandatory divestiture of all network assets - generally referred to as Ownership Unbundling - would be the logical (since most effective) consequence (OECD, 2001; Mulder and Shestalova, 2006; Buchan, 2007; European Commission, 2007a, 2007b, 2007c, 2007d; Pollitt, 2008). But when the Third Electricity Directive ${ }^{1}$ (European Union, 2009) required member states to implement one of three possible models further tightening the previous unbundling rules for transmission lines, several countries surprisingly refrained from choosing Ownership Unbundling, although it was one of the legal alternatives. Instead, these states mainly opted for the Independent Transmission Operator (ITO) model (see Table 1 on the next page), which basically just amounts to a stricter enforcement of the Legal Unbundling provisions already mandatory before ${ }^{2}$; Legal Unbundling requires vertically integrated companies to spin off their grid monopolies into separate entities (European Union, 2003; European Commission, 2004).

Our paper provides a possible explanation for the rather puzzling choice of some member states to keep their power utilities integrated to the highest degree that European legislation permits: based on a theoretical analysis, we argue that the decision to either implement Ownership Unbundling or adhere to Legal Unbundling depends on the objective the authority determining the level of vertical separation pursues.

\footnotetext{
${ }^{1}$ This is the commonly used shortening of the directive's official name, "Directive 2009/72/EC of the European Parliament and of the Council of 13 July 2009 concerning common rules for the internal market in electricity and repealing Directive 2003/54/EC".

${ }^{2}$ Authors classifying the ITO model just as a (strict) form of Legal Unbundling are, e.g., Geldhof and Vandendriessche (2008), Höffler and Kranz (2011a), Meyer (2012) and Brunekreeft et al. (2014).
} 


\begin{tabular}{|l|l|}
\hline Unbundling Regime & Countries $^{3}$ \\
\hline Ownership Unbundling & $\begin{array}{l}\text { BEL, CZE, DNK, EST, ESP, FIN, GBR } \\
\text { LTU, NLD, ITA, }\end{array}$ \\
\hline both & AUT, DEU \\
\hline Legal Unbundling/ITO & BGR*, CYP**, FRA, GRC, HUN, LUX** \\
\hline
\end{tabular}
Notes: Data stem from the Commission's information on its certification
of European TSOs (European Commission, 2014a) that is required by the
Third Electricity Directive (European Union, 2009); they reflect the state of
facts as of February 2014. * In these countries, the certification process is still
pending; data are obtained from European Commission (2014c) (BGR), URE
(2013) (POL), ERSE (2013) (POR) and JARSE (2013) (SVN). ** Both the
Cypriot and the Luxembourgian TSO are exempted from the new, stricter
rules on unbundling (European Union, 2009; de Hauteclocque and Ahner,
2012), but are obliged to be separated legally (European Commission, 2014d,
2014e). *** In the UK, Ownership Unbundling is only implemented in Eng-
land and Wales. The TSOs in Scotland and Northern Ireland are certified
under a vertical structure deviating from the three unbundling models pro-
vided for in the Third Directive; see footnote 3 for further details.

Table 1: Legal and Ownership Unbundling in EU member states

By considering the relationship between regulatory goals and the type of unbundling this paper aims at contributing to the discussion about one of the recent core topics in the area of EU energy regulation. Especially after the results of an Energy Sector Inquiry (European Commission, 2007b) had been published in 2007, the European Commission vigorously called for transmission lines unexceptionally separated by ownership; the Inquiry, launched in 2005 to monitor the efficacy of regulations already implemented by this time (European Commission, 2005), revealed significant deficiencies in the functioning of national electricity markets and serious delays in the realization of the intended single European market. Consequently, the Commission made clear that it rated the then-valid combination of Accounting, Functional and Legal Unbundling ${ }^{4}$ as insufficient, judging Ownership Unbundling as the only way to once

\footnotetext{
${ }^{3}$ Apart from the countries listed, Latvia and Romania opted for the third model provided for by the Third Electricity Directive, the Independent System Operator (ISO) (European Commission, 2014a): under this regulatory regime, the ownership of the transmission system remains with the integrated utility, but an organization fully detached from the (legally separated) affiliated group is responsible for the system's operation, maintainance and development (European Union, 2009). Due to its minor relevance in Europe, the ISO is neglected in the following. On Malta no transmission grid exists (European Commission, 2014b). Moreover, derogations from the unbundling provisions were granted to the Irish (European Commission, 2013a), the Northern Irish (European Commission, 2013b) and the Scottish (European Commission, 2012) transmission system operators (TSOs), since the Commission rated the models implemented in these countries as guaranteeing a higher degree of TSO independence than the least strict regime provided for by the Third Electricity Directive, the ITO: in each case, transmission system operation is shared between a legally unbundled entity owning the grid and another, entirely separated company.

${ }^{4}$ In addition to Legal Unbundling, the immediate predecessor of the Third Electricity Directive demanded separate accounts for transmission and distribution activities (a measure denoted as "Accounting Unbundling") as well as the realization of several provisions subsumed under the term "Functional Unbundling": the preservation of a strict confidentiality with respect to comercially sensitive information gathered in the line businesses; the absence of any interference from the associated generation, wholesale or retail activities in decisions regarding the networks (like construction or maintenance); the endowment of distribution and transmission businesses with
} 
and for all terminate any undue preference of associated non-network activities by transmission monopolies (European Commission, 2007a, 2007b, 2007c, 2007d). Research on unbundling supported the Commission's view and identified even further substantial advantages of entirely separated networks: a facilitation of regulation and privatization as well as a stronger focus of the different activities on their own business that, inter alia, enhances the security of supply. Potential disadvantages such as a possible increases in capital cost for separated firms, a facilitation of foreign takeovers and transaction costs due to contract renegotiations and necessary in-house reorganizations were seen as rather less serious ones (Pollitt, 2008; see also Mulder and Shestalova (2006) for most of the pros and cons mentioned). However, in general, solely the market participants benefiting from persisting linkages between network and non-network activities were blamed for delays in the realization of Ownership Unbundling: the just legally separated incumbents (European Commission, 2007b). Other actors that might potentially be interested in hampering liberalization as well, on the contrary, were rather ignored: for example, captured regulators acting in the interest of integrated companies due to bribes (Laffont and Tirole, 1991), posttenure job prospects in the industry (Che, 1995) or by intentionally applying biased information provided by the regulatees as a basis for regulatory decisions (Agrell and Gautier, 2010, 2012a, 2012b). By shedding light on the role agencies play in the process of network separation, this paper might hence add an important aspect to the discussion that has been neglected up to now.

By explicitly analyzing the decisions of the regulatory authority, the paper furthermore aims at contributing to the existing theoretical literature on Legal and Ownership Unbundling. In a nutshell, model results up to now are, rather surprisingly, far from being supportive of the consumer-benefiting effect ascribed to a full separation of monopolistic from (potentially) competitive stages of the value chain. But what is at least as surprising is that in all theoretical analyses questioning the benefits of Ownership Unbundling both the regulators and their rulings play, at best, a minor role.

The paper of Cremer and De Donder (2013) is a typical example of both these unexpected features of current research: their findings suggest that both the network capacity and the output of the final good are lower and the price of the end-product is higher when an upstream monopolist providing the network as an essential input for downstream suppliers is separated by ownership instead of just legally. However, at the same time, an authority does not really come into the picture at all: the network access fee is not determined by a regulator, but by the monopolistic grid firm itself.

That an abandonment of Ownership Unbundling can be beneficial for electricity consumers

separate and sufficient funding and personnel; and decision-makers in the grid activities not affected by potential financial or occupational interests in any non-network business (European Union, 2003; European Commission, 2004). 
is also Bolle and Breitmoser's (2006) conclusion when they draw on figures from the EU power sector to interpret their model results. Their general findings inter alia show that Legal Unbundling is the suboptimal type of separation (i.e., leads to lower quantities and higher prices of the final product) when the regulatory inefficiency supposed to be associated with an only legally separated utility is high; the assumption that regulatory surveillance under Legal, but not under Ownership Unbundling is poor and entails a network usage charge always exceeding the upstream firm's costs of provision is a key feature of the theoretical framework. That is, the model does not allow for the licensing of the optimal usage charge by the authority under one of the two regimes of interest; this, in turn, prevents a proper comparison of both types of vertical separation.

Also Höffler and Kranz (2011a) assume a deficient regulation to prevail: independent of the regime, the monopolist in their model is able to subtly sabotage its downstream demanders to increase their costs. Operationalizing Legal Unbundling as a parent company that maximizes joint profits of both its own and the separated division's activity while the legally unbundled affiliate solely considers its own profits (as first introduced by Sibley and Weisman (1989)), their main finding then reveals that it matters whether the upstream or the downstream activity of a formerly integrated utility is separated: while a legally unbundled downstream firm together with a monopolistic parent company results in a (weakly) lower final good output than that obtained under Ownership Unbundling, a downstream parent company with a legally separated affiliate active in the industry's monopoly area results in a (weakly) higher one. Throughout the analysis, identical usage charges for Legal and Ownership Unbundling are assumed, although it is at least briefly shown in the end that the outlined result also holds when the respective optimal fee is set under both regulatory regimes. The identification and the comparison of these optimal choices, though, is lacking in the paper as well.

Finally, Höffler and Kranz (2011b) study what they call "imperfect" Legal Unbundling for the scenario where the downstream supplier is the parent of a separated upstream monopolist which is again able to subtly sabotage; however, unlike as in Höffler and Kranz (2011a), the downstream firm no longer has to be the single shareholder. What makes the regulatory measure "imperfect" is that not only the parent company takes account of the unbundled division's profits in its decision-making, but that this also happens the other way round (in a different extent, depending on the level of "imperfection"). Differentiating between a situation where the downstream firm's share affects the upstream monopolist's objective to allow for its parent's profits and another one where this is not the case, the following insights are of interest: without any influence of the share, the output of the final good weakly increases with a higher share as long as the upstream firm's weight on downstream income is not overly high; this contradicts a full ownership separation at least for (mid and) low levels of "imperfection". When, on the contrary, an influence exists, maximum production is not realized with a stand-alone monopolist when generic cases are 
considered; requiring full Ownership Unbundling would hence be suboptimal, again. Once more, however, all results are obtained without attaching great importance to authority decisions: a determination of optimal grid charges for different share sizes and "imperfection" levels does not take place at all; instead, the charge is assumed not to vary.

Besides the disregard of regulatory decisions on optimal access fees the narrow choice of the criteria the two unbundling regimes are evaluated against in the four mentioned papers stands out. Without exception, the assessment is solely carried out on the basis of classical textbook objectives of consumer-friendly authorities: a large network capacity as well as both a high output and a low price of the consumption good. That is, regulations possibly implemented by authorities acting in their own interest or to the benefit of market participants other than consumers are entirely neglected.

This paper extends the two-stage models common in theoretical analyses on Legal and Ownership Unbundling to figure out how empowering the regulatory agency to set the grid charge and the goal the agency aims for affect the optimal choice on the type of vertical separation. Before the upstream monopolist decides on the grid capacity and the generators, requiring the network to dispatch electricity and modelled as a Cournot duopoly, subsequently realize their production, the regulator included in our theoretical framework implements its rulings: it demands the monopolistic network to be separated either legally (what makes the grid firm become the parent company, taking account of the affiliate's profits) or by ownership and licenses the access fee optimal under the respective type of unbundling chosen before. In particular, all decisions the agency takes in the stages added in our model depend on the objective the authority pursues: we differentiate between "traditional" consumer-oriented goals (a high output, a low price or a high consumer surplus) and targets benefiting the government (high tax yields) or the industry (high company profits); we argue that especially the advantages associated with a departure from "traditional" objectives such as potential increases in state appropriations in the course of growing public revenues or bribes and posttenure job prospects for captured regulators issuing producer-friendly provisions might induce the authority to ignore its official mission of end-user protection.

The results reveal that, regardless of the regulator's goal, the optimality of one or the other type of vertical separation depends on the level of the network charge if this is set identically under both regulatory regimes. When, according to the agency objective, the optimal access fee is licensed for both degrees of separation, the model shows that a grid unbundled by ownership is unambiguously superior to a legally separated one solely when the authority strictly acts in the interests of consumers (i.e., pursues the "traditional" aims of regulation); if, on the contrary, only the benefits of the industry or the government (and hence indirectly its own interests) are relevant for the regulator, Legal and Ownership Unbundling are equivalent in virtually all cases. Minor disadvantages and costs associated with a change in the ownership structure of 
just legally unbundled utilities could then result in the status quo to be preferable to full vertical separation, letting authorities focusing on business-oriented or government-oriented goals be a possible explanation for the adherence of several European countries to Legal Unbundling.

The remainder of the paper is organized as follows: the next section justifies the choice of the different objectives attributed to the authority and discusses the regulatory goals in more detail. Section 3 sets outs our four-stage model and analyzes the optimal decisions of the downstream duopoly and the monopolistic upstream network; this allows us to derive the market outcome for every possible access fee. Based on these results, Section 4 then studies the agency's optimal choices of the grid charge and the unbundling regime for each of the objectives the regulator might pursue; possible explanations for the differences in the degree of vertical separation across EU member states as well as potential measures enhancing the focus of agencies on consumeroriented goals are subsequently provided. Section 5 concludes. Proofs can be found in the Appendix.

\section{Regulatory Objectives}

\subsection{Consumer-Oriented Objectives}

We start our account of potential regulatory objectives with an illustration of the goals that are in line with the essential function typically assigned to regulators: the representation and promotion of consumer interests (Newbery, 1999, ch. 4.1; Small, 1999; Decker, 2010; Albon, 2012). The related literature and the mission descriptions of energy regulators active in EU member states indicate that three such targets can be discerned:

Maximizing the electricity dispatch: One of the basic objectives of regulatory interference is the prevention of anti-competitive behavior of dominant market players (as, e.g., incumbents) supplemented with a persistent promotion of competition in all those production stages where more than one firm can survive (Kay and Vickers, 1990; Small, 1999; Albon, 2012; see also the goals declared by the European Agency for the Cooperation of Energy Regulators (ACER, 2014), the Council of European Energy Regulators (CEER, 2014) and the German Bundesnetzagentur (BNetzA, 2014)). By this means, it shall (inter alia) be ensured that the consumers' demand for the product traded on the regulated market is fully satisfied (Newberry, 1999, ch. 4.1.1; Joskow, 2007; MIT, 2011, ch. 8.1). However, due to the power suppliers' need for grid capacity, realizing this aim in case of electricity implies that the authorities' interventions are not restricted to just monitoring both producers and sellers of the final good; instead, it additionally requires the surveillance of the monopolistic grid activities. Without regulation, network companies would restrain capacity to the profit-maximizing monopoly amount only (Demsetz, 1968; Kay and Vickers, 1990; Breyer, 1998; Ogus, 2004, ch. 3.2), which would of course lead to an undersupply 
of electricity as well.

Minimizing the power price: The outlined objective of maximizing output is closely related to another fundamental target of regulatory authorities: ensuring low commodity prices to protect consumers from excessive mark-ups otherwise claimed by firms with market power (Kay and Vickers, 1990; Small, 1999; Newbery, 1999, ch. 4.1.1). Related to electricity markets, the importance of this aim becomes obvious in the mission descriptions of European energy regulators: they, inter alia, require the authorities to guarantee power prices that are "fair" (ACER, 2014; CER, 2014 (IRL); URSO, 2014 (SVK)), "cost-reflective" (ACER, 2014), "competitive" (Energiemyndigheten, 2014 (SWE)) and "on an affordable level" (MEKH, 2014 (HUN)), to ensure a "low-priced [...] supply of electricity" (BNetzA, 2014) or to "protect the interests of consumers [...] with respect to prices" (ERSE, 2014 (POR)). With the costs of network access being passed on to final customers by power suppliers, a core remit of electricity price regulation is the stringent control of the usage fee demanded by bottleneck owners: this is the only way to prevent that monopoly prices are claimed for granting capacity (Demsetz, 1968; Trebing, 1977; Kay and Vickers, 1990; Breyer, 1998; Newbery, 1999, ch. 4.1; Ogus, 2004, ch. 3.2; Joskow, 2007) while, at the same time, providing network companies with the financial means they need to construct and maintain all necessary assets (Breyer, 1998; Newbery, 1999, ch. 4.1; Small, 1999; Joskow, 2007; MIT, 2011, ch. 8.1).

Maximizing consumer surplus: The third possible goal finally combines the first two: the consumer surplus increases with higher amounts of output and lower end-user prices. Taking the surplus as the item to maximize in our theoretical anaysis allows for an appropriate operationalization of the above-mentioned target of promoting consumer interests prevalent in the literature as regulatory core objective (Newbery, 1999, ch. 4.1; Small, 1999; Decker, 2010; Albon, 2012). The exceptional significance this task actually has also in electricity market regulation is reflected in the frequency its fulfillment is named as a central aim of the European agencies' activities: numerous authorities emphasize their endeavors to protect, fortify and benefit endusers by their monitoring operations (ACER, 2014; AEEG, 2014 (ITA); BNetzA, 2014; CER, 2014; CNMC, 2014 (ESP); Energiemyndigheten, 2014; Energitilsynet, 2014 (DEN); ERSE, 2014; ERÚ, 2014 (CZE); JARSE, 2014 (SVN); MEKH, 2014; Ofgem, 2014 (GBR); RAE, 2014 (GRC); URSO, 2014).

\subsection{Business-Oriented Objectives}

Maximizing industry profits: Although responsible for serving the consumers in the first instance, regulatory authorities might take account of industry profits as well: in several cases, an agency's mission is expected to require welfare or total surplus maximization (Train, 1991, chs. I.1 and I.3; Small, 1999; Joskow, 2007) or - which basically amounts to the same thing - 
the maximum possible reduction of dead-weight losses induced by market failures (Noll, 1989; Kay and Vickers, 1990); under both mandates, not only consumer surplus but also producer surplus is crucial. An authority will likewise consider company earnings in its decision when regulatory statutes demand to act in the "public interest" (Mitnick, 1980, chs. I.1.2 and V.1.0; Noll, 1989; Kay and Vickers, 1990): in general, scholars rate this provision as being an equivalent to welfare or total surplus maximization (Mitnick, 1980, ch. V.3.0; Noll, 1989; Train, 1991, ch. I.1; Newbery, 1999, ch. 4.1).

But not only the fulfillment of an official mission demanding welfare maximization might cause an authority to strive for high industry profits. Agency employees might also pursue own interests and objectives that are at odds with the statutory mandate of their employer (Noll, 1989; Kay and Vickers, 1990; Train, 1991, ch. I.1) and therefore focus on maximizing the power producers' and the network monopolist's profits. This might, for example, happen when the companies in the electricity sector succeed in using the authority for their own ends and induce the regulatory decision-makers to act and rule only in the firms' interests (Stigler (1971) was the first one addressing this potential abuse of regulation; see also Mitnick, 1980, chs. I.2.0, V.1.0 and V.2.0; Rourke, 1984, ch. 7; Kay and Vickers, 1990).

The reasons for such a regulatory capture can, as already indicated in the introduction, be rather diverse: in Laffont and Tirole (1991), the regulatee bribes the authority to achieve a more profitable regulation (Kay and Vickers (1990), maybe somewhat less precarious, just mention an employment of company resources by supervised firms to advantageously affect regulatory decisions). Che's (1995) model, including a "revolving door" (i.e. a regulator's posttenure opportunity to work in the sector under surveillance), suggests a less intense monitoring when the official's control efforts reduce the time and resources available to acquire skills valuable for the industry (and thereby the regulator's chance of getting hired); likewise, a laxer regulation occurs in case of an exogenous and unobservable posttenure competence as long as the negative relationship between the regulator's industry qualification and the intensity of supervision prevails ${ }^{5}$. (For a short non-theoretical discussion of the issues arising with a potential industry employment of retired regulators see also Noll (1989).) And finally, Agrell and Gautier (2010, 2012a, $2012 \mathrm{~b}$ ) assume the authority to make use of biased information provided by the regulatee for free in order to save agency resources and working time, simultaneously accepting a suboptimal regulation derived from these noisy data.

\footnotetext{
${ }^{5}$ However, the existence of a revolving door can also lead to a stricter supervision: this is the case whenever posttenure competence also increases monitoring efficiency (independent of whether industry knowledge has to be acquired or is given exogenously); and also in a setting without any postagency qualification where the door's porosity corresponds to the probability of a successful collusion between regulator and regulatee an entirely closed door is suboptimal as long as the government's financial means to correctly incentivize officals are limited (Che, 1995). In addition, also Salant's (1995) model assuming a company-funded consulting activity for retired regulators suggests a (weak) welfare-enhancing effect of revolving doors.
} 
However, unlike in the different strands of the capture literature, bribes, wage payments from postagency industry employment or (biased) information flows between regulated firms and regulator are not included in our model; instead, we simply operationalize regulatory capture by imputing an interest in high industry profits to the authority, implicitly assuming that the regulatees will benefit the regulator in return for decisions taken to favor the companies. For analytical convenience, upstream and downstream profits are discussed separately in the model section.

\subsection{Government-Oriented Objectives}

Maximizing revenues from electricity taxation: Finally, it might also be possible that the regulator focuses on the maximization of revenues generated from taxing electricity. The surveys of Johannsen et al. (2004), the CEER (2005) and Gilardi (2008, ch. 8) show that many European energy regulators are fully or at least partially funded by the government, and the OECD/IEA (2001) argues that the state's income from general taxation is an important source for this funding. As an increase in the national budget (which, in turn, is usually raised in times of high tax yields) is furthermore expected to be associated with an increase in agency budgets (or, at least, a lower probability that their requests for additional resources are denied) (Downs, 1967, ch. IX; Blais and Dion, 1990; Bowling et al., 2004; Wildavsky and Caiden, 2004, ch. 3), higher tax revenues might imply a better financial endowment of the regulatory authority, too.

The authority's intention behind its striving for higher means can be twofold: on the one hand, it might inherently be driven by the regulator's public mission. In this case, higher appropriations (are perceived as being necessary to) raise the agency's capability of competing with companies for specialists (Smith, 1997) indispensable in today's utility regulation due to the steadily increasing complexity of this task (Thatcher, 2002a) and of covering the substantial information costs that arise in this field (Agrell and Gautier, 2010). With adequate monetary and personnel resources being rated as vital for an agency to properly fulfill its function (Rourke, 1984, ch. 4; OECD/IEA, 2001; Thatcher and Stone Sweet, 2002), the regulator's behavior might then be explained by a pursuit of an equality of arms in the struggle against financially potent (Thatcher, 2002b) regulatees.

On the other hand, the regulator's wish for higher appropriations might - just as the potential interest in high industry profits - also be caused by purely self-serving motives: agency employees are, as Ogus $(2004$, ch. 4.4) points out, typically bureaucrats that, in turn, might act as suggested by Niskanen $(1968,1975)$ and aim at a maximized budget to finance, e.g., higher salaries or perquisites (see also Migué and Bélanger (1974), Rourke (1984, ch. 4) and Tullock et al. (2002, ch. 5) on that topic; Noll (1989) and Train (1991, ch. I.1) explicitly state the possibility of regulators behaving as officials à la Niskanen).

At least for bureaucrats in general, empirical evidence seems to support this conjecture 
in many cases: several papers reveal a striving for mostly considerable budget increases by various American agencies (Sharkansky, 1965, 1968; LeLoup and Moreland, 1978; Lauth, 1986; Thompson, 1987; Ryu et al., 2007; ASAP, 2008). Blais and Dion (1990) expect a bureaucratic self-interest to exist after (inter alia) reviewing the results of Krueger (1988), showing the number of applicants for U.S. federal jobs to increase when public compared to private wages increase, and Sigelman (1986), suggesting an eagerness for higher agency means to prevail among most American senior administrators. And finally, Bowling et al. (2004) and the American State Administrators Project's survey of 2008 (ASAP, 2008) do not only find a broad majority of U.S. agency heads favoring higher expenditures for their own authority (which, according to Ryu et al. (2007), strongly affects an office's request for a rising budget), but also that many of them likewise prefer a higher overall public spending. For Europe, Venetoklis and Kiander (2006) results suggest that Finnish higher-level officials especially advocate higher appropriations for tasks fulfilled by their agency, and also Bağdigen's (2003) interviews with Turkish local officials reveal a desire for budget expansions for their own authorities. Jacobsen (2006) finds that Norwegian municipal bureaucrats favor increasing public expenditures in general and prefer these means to be allocated to their own remit as well as to internal administration (expected to be used to increase the bureaucracy's slack).

The problem of self-serving regulators might be even aggravated in the near future due to the growing number of highly skilled experts employed in utility authorities: such specialist are, according to Moe (1989), especially inclined to pursue personal objectives, confident that laymen outside their agency lack the knowledge to control them.

\section{The Model}

To provide a possible explanation for the variations in regulatory regimes across countries we analyze a multi-stage model that focuses on the differences between Legal and Ownership Unbundling from the perspective of the institution prescribing the intensity of vertical separation - the national regulatory authority. The structure of the model, which will be solved by backward induction in this and the next section, is illustrated in Figure 1 and can be described as follows: a regulator strives for the realization of one of the objectives elucidated in the previous section (a high electricity dispatch, a low power price, a high consumer surplus, high revenues from electricity taxation or high industry profits). The agency takes ac-

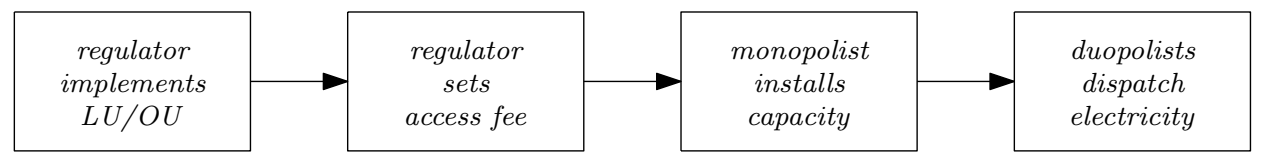

Figure 1: The Stages of The Game 
count of this goal when it determines whether Legal (LU) or Ownership Unbundling (OU) is implemented in the national electricity market in the first stage (which is discussed in Section 4.2). Subsequently, the authority sets the network access charge; as the type of unbundling, also the level of the fee is chosen so as to achieve the respective regulatory objective in the best possible way (Section 4.1). The licensing power assigned to the agency due to its market surveillance task allows for the enforcement of the charge that is optimal for the regulator. The grid company obligated to abide by the authority's decision hence faces an exogenously given fee as in Bolle and Breitmoser (2006) and Höffler and Kranz (2011a, 2011b); the full coverage of the construction costs via the usage charge assumed in these three papers independent of the network size, though, is no longer ensured due to the regulator's unconstrained second stage decision.

The third and the fourth stage, then, analyze the choices of the companies in the electricity industry. Since these stages are also considered in the papers on vertical separation that neglect the role of regulators, several of their assumptions and approaches of how to model different aspects of unbundling are adopted. As in Cremer and De Donder (2013), we assume the power sector to consist of one upstream monopolist that provides the grid and a downstream duopoly of identical generators that satisfies electricity demand and requires the network to dispatch power; with Legal Unbundling, one of the duopolists is an affiliate of the grid company, whereas in the case of Ownership Unbundling both generators are completely independent.

In the third stage, the upstream monopolist maximizes profits by deciding on the network capacity. A grid company that is just legally unbundled maximizes the overall profits of both the network and the affiliated generator (Section 3.2.1); a grid company separated by ownership, on the contrary, solely maximizes its own profits (Section 3.2.2). In the last stage, then, the network units are purchased by the downstream duopolists; each of them solely maximizes its own profits (Section 3.1), independently of which type of unbundling is implemented (Höffler and Kranz (2011a) ${ }^{6}$; Cremer and De Donder (2013); both papers borrow the modeling approach for Legal Unbundling originally introduced in Sibley and Weisman (1998)). When deciding on their power production, the generators consider that for every electricity unit they dispatch one unit of grid capacity is required. For each network unit, the duopolists have to pay the fixed per-unit fee (Bolle and Breitmoser, 2006; Cremer and De Donder, 2013; Höffler and Kranz, 2011a, 2011b) set by the regulator in the second stage; it is, as in reality (see, e.g. Sakhrani and Parsons $(2010)^{7}$ ), assumed to be independent of the electricity price. In cases where insufficient

\footnotetext{
${ }^{6}$ To be precise, Höffler and Kranz (2011a) denote the setting equivalent to that analyzed in our paper (i.e., with an upstream monopolist maximizing total profits of the network and the legally separated downstream firm) as "reverse unbundling", while in their legal unbundling scenario the downstream producer maximizes joint profits.

${ }^{7}$ Sakhrani and Parsons (2010) analyze the network tariffs of four OECD countries in much detail; for both the EU member states included in their selection, Portugal and Spain, they find total access fees to be a mark-up on the power price paid by consumers that solely consist of price-independent capacity charges $(€ / \mathrm{kW} /$ year,
} 
capacity constrains the power production, we finally suppose the two downstream generators to share the existing network units equally (Cremer and De Donder, 2013).

\subsection{The Downstream Market}

In the fourth stage, the two downstream generators, $i=1,2$, produce the electricity outputs $q_{i}$ that add up to a total power supply of $q_{1}+q_{2}=Q$. When taking their production decisions, the duopolists face an inverse aggregate demand function $P(Q)$ that we assume to be decreasing and strictly convex (so that $P^{\prime}(Q)<0$ and $P^{\prime \prime}(Q)>0$ ). This implies a reduction in electricity consumption after power price increases, as it is also suggested by recent empirical findings on the price elasticity of electricity demand for several EU member states (see below; we refer to long-run values since the decision on a potential change in the regulatory regime as well as its eventual implementation is a long-term process); the price elasticity, defined as

$$
\epsilon=\frac{P}{Q(P)} \cdot \frac{\partial Q(P)}{\partial P}<0
$$

(with $Q(P)=P^{-1}(P)$ ), describes the percentage change in electricity demand in response to a one percent increase in the power price (Varian, 2010, ch. 15.5).

For Austria, Denmark, Germany, Ireland, the Netherlands, Portugal (Madlener et al., 2011), Cyprus (Zachariadis and Pashourtidou, 2007), France, the UK (Narayan et al., 2007; Madlener et al., 2011), Greece (Hondroyiannis, 2004; Madlener et al., 2011), Spain (Madlener et al., 2011; Blázquez et al., 2012) and Italy (Narayan et al., 2007; Madlener et al., 2011; Dicembrino and Trovato, 2013), the long-run price elasticity of household electricity demand is found to be negative and inelastic; results indicate the same for the long-run price elasticity of industrial power demand in Greece (Christopoulos, 2000; Polemis, 2007), Italy (Dicembrino and Trovato, 2013), Cyprus (Zachariadis and Pashourtidou, 2007; restricted to the service sector) and Germany (Madlener et al., 2011; only for food and tobacco, chemicals, pulp and paper, non-metallic minerals and transport equipment as subsectors of manufacturing). A negative and elastic long-run price elasticity of residental electricity demand is furthermore suggested for Finland (Madlener et al., 2011) and Germany (Narayan et al., 2007).

In our model, the per-unit price $P(Q)$ paid by electricity consumers includes an ad-valorem tax with a tax rate $t$, so that the revenue a generator earns per power unit is equal to $(1-t) \cdot P(Q)$. Each duopolist incurs generating costs $C\left(q_{i}\right)$, with the cost function assumed to be strictly convex and increasing, $C^{\prime}\left(q_{i}\right)>0, C^{\prime \prime}\left(q_{i}\right)>0 \forall q_{i}$; this reflects the merit order of generation, i.e. the disproportionately increasing marginal costs of the power plants gradually connected to the

$\overline{€ / \mathrm{kW} / \text { month and } € / \mathrm{kW} / \text { day), fixed charges }}(€ /$ year, $€ /$ month and $€ /$ day) and charges raised by consumption volume $(€ / \mathrm{kWh})$ (with their particular composition depending on both the country and the customer category). 
grid to satisfy an increasing demand (Sherman, 2008, ch. 18.1). Finally, for every network unit employed due to the required one-to-one relationship between supplied electricity and grid capacity, the generators have to pay the access charge $a$ the upstream monopolist is entitled to raise to be able to construct and maintain the grid.

We assume the duopolists in the downstream market to compete in quantities. Since the generators take their decisions independently of the unbundling regime, fourth stage results hold for both types of vertical separation. Three different cases then have to be distinguished: in the first case, the network size exceeds the total amount of electricity the two generators dispatch; the grid capacity, denoted by $X$ in the following, does not constrain power production. Consequently, the duopolists play a simple Cournot game and solve the maximization problem

$$
\max _{q_{i}^{*}} \pi_{i}=\pi_{i}\left(q_{1}, q_{2}\right)=(1-t) \cdot P(Q) \cdot q_{i}-a \cdot q_{i}-C\left(q_{i}\right) .
$$

In equilibrium, the duopolists' generation levels $q_{1}^{*}(a)$ and $q_{2}^{*}(a)$, respectively, satisfy the first-order conditions

$$
a+C^{\prime}\left(q_{i}\right)=(1-t) \cdot\left[P(Q)+P^{\prime}(Q) \cdot q_{i}\right] \wedge q_{1}+q_{2}=Q \quad \text { for } i=1,2,
$$

so that the generators' marginal costs equal their marginal revenues: the access charge and the production costs for the additional electricity unit add up to the former, whereas the latter includes the net price for the marginal power unit and the net price reduction for all inframarginal supplies resulting from the increase in generation. The duopolists' equilibrium power supplies sum up to the total electricity amount in the unconstrained equilibrium, $Q^{*}(a)$; since a symmetric duopoly is assumed, $q_{1}^{*}(a)=q_{2}^{*}(a)=\frac{Q^{*}(a)}{2}$ holds.

In the second case, the network capacity exactly equals the overall power production of both duopolists in the Cournot equilibrium; this again allows the generators to dispatch $q_{1}^{*}(a)=$ $q_{2}^{*}(a)=\frac{Q^{*}(a)}{2}$ units of electricity.

In the third case, the grid size finally undercuts $Q^{*}(a)$ and constrains the power production. As described above, we assume the duopolists to split the existing capacity equally in this situation, so that $\frac{X}{2}$ electricity units are supplied by each generator.

We can summarize the three cases as follows: let $Q(a, X)$ denote the actual amount of electricity dispatched; then,

$$
Q(a, X)= \begin{cases}Q^{*}(a) & \text { if } Q^{*}(a)<X \\ Q^{*}(a)=X & \text { if } Q^{*}(a)=X \\ X & \text { else }\end{cases}
$$




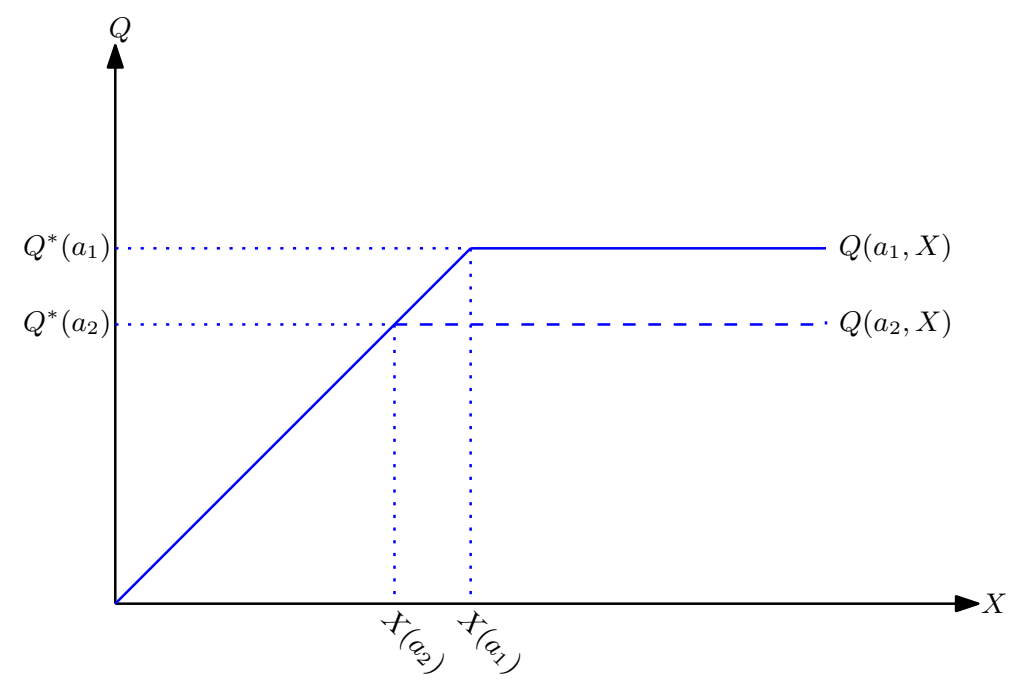

Figure 2: POWER Dispatch AND GRID CAPACITY FOR $a_{1}<a_{2}$

With a network size not constraining downstream generation in the first two cases, each duopolist is able to realize its profit-maximizing production level $q_{i}^{*}(a), i=1,2$; accordingly, $\frac{\partial \pi_{i}}{\partial q_{i}}=0, i=1,2$ holds in (i) and (ii). In the third case, though, a capacity constraining the dispatch of power prevents the production of the profit-maximizing electricity amounts and the generators can only choose (identical) outputs smaller than $q_{i}^{*}(a), i=1,2$; hence, $\frac{\partial \pi_{i}}{\partial q_{i}}>0, i=1,2$ follows in (iii).

The cases are illustrated in Figure 2: starting from the origin (and no network), an increase in the grid capacity enables the generators to raise their profits by expanding production to a level closer to the unconstrained Cournot equilibrium output; accordingly, all additional grid units are purchased by the power producers and the $Q\left(a_{1}, X\right)$-function has a slope of one in case (iii). When the function's kink, representing the second case, is then reached, the enlargement of generation is stopped: in this point, the network provided by the upstream monopolist is just equal to the aggregate downstream output that maximizes the duopolists' profits. Consequently, any further increases in $X$ do not affect the production decision of the generators; they do not acquire more than $Q^{*}\left(a_{1}\right)$ grid units and with a non-binding capacity constraint (case (i)) the graph of the function becomes horizontal. The above considerations finally allow us to derive how the actual total power supply $Q(a, X)$ reacts to a marginally higher network capacity $X$ :

$$
\frac{\partial Q}{\partial X}= \begin{cases}0 & \text { in (i) } \\ 1 & \text { in (iii) }\end{cases}
$$

The results for cases (i) and (iii) are straightforward. For case (ii), the derivative is not defined since $Q\left(a_{1}, X\right)$ is nondifferentiable at the kink point where $X=Q^{*}\left(a_{1}\right)$. 
In addition, we can analyze the reaction of $Q(a, X)$ on marginal increases in $a$. We get

$$
\frac{\partial Q}{\partial a}= \begin{cases}\frac{\partial Q^{*}(a)}{\partial a}<0 & \text { in (i) } \\ 0 & \text { in (iii) }\end{cases}
$$

In the first case, a higher usage fee reduces the total dispatch of electricity: the excess capacity allows the duopolists to realize their unconstrained Cournot equilibrium outputs. Since these decrease as soon as the generators face higher marginal costs, production in the unconstrained equilibrium and therefore also the actual total power supply is reduced whenever the access charge is increased (see Appendix A1 for a derivation). Accordingly, a higher a leads to a parallel downward shift of the horizontal part of the $Q(a, X)$-function (as an example, see the dashed graph in Figure 2 that emerges after the fee is increased from $a_{1}$ to $a_{2}$ ). In case (ii), the reaction is again not well-defined due to the the function's kink. In case (iii), finally, downstream output does not change. As in the first case, generation levels in the unconstrained Cournot equilibrium are reduced by an increase in the usage charge; but since $Q(a, X)$ is cut back below $Q^{*}\left(a_{1}\right)$ before due to the capacity constraint, the reductions in the unconstrained equilibrium outputs are not reflected in a lower network demand by the duopolists. Instead, the generators continue to exploit the existing grid completely.

\subsection{The Upstream Monopolist}

In the third stage, the upstream monopolist installs the capacity $X$ that maximizes either total profits of the network and the affiliated generator (under Legal Unbundling) or network profits alone (under Ownership Unbundling). The monopolist generates revenues by selling capacity to the generators for the per unit price $a$; the costs to construct and maintain the grid are described by the cost function $G(X)$, which is assumed to be strictly convex and increasing, $G^{\prime}(X)>0, G^{\prime \prime}(X)>0$. In the following, we use the subscripts $L$ and $O$ to distinguish network sizes and access fees under Legal and Ownership Unbundling, respectively.

\subsubsection{Legal Unbundling}

When statutory provisions require Legal Unbundling, the maximization of the aggregated upstream and downstream profits by the network company yields the optimization problem

$$
\begin{aligned}
\max _{X_{L}^{*}} \pi_{v}\left(X_{L}\right)= & a_{L} \cdot Q\left(a_{L}, X_{L}\right)-G\left(X_{L}\right) \\
& +(1-t) \cdot P\left(Q\left(a_{L}, X_{L}\right)\right) \cdot \frac{Q\left(a_{L}, X_{L}\right)}{2}-a_{L} \cdot \frac{Q\left(a_{L}, X_{L}\right)}{2}-C\left(\frac{Q\left(a_{L}, X_{L}\right)}{2}\right),
\end{aligned}
$$


with $\pi_{v}$ denoting the total profits of the legally unbundled utility. The first line of (6) describes both revenues and costs of the grid company: for all electricity units the generators dispatch (adding up to either $X_{L}$ if the network size constrains power production or $Q^{*}\left(a_{L}\right)$ if not), the monopolist earns the access fee $a_{L}$. Furthermore, the monopolist incurs the costs for providing $X_{L}$ units of grid capacity, independent of whether the whole or only a part of the network is eventually used by the downstream duopolists. The second and the third line of (6) then add both revenues and costs of the affiliated generator and include therefore all the components that are familiar from the duopolists' maximization problem (see (2)): the affiliate earns the net price for the electricity units it sells and has to bear both the access fees for all these units and the associated generation costs. Due to the duopolists' symmetry, always half of the actual total power production $Q\left(a_{L}, X_{L}\right)$ is supplied by the affiliated generator, regardless of whether generation is constrained by the network or not.

With the optimal grid capacity, $X_{L}^{*}$, marginal costs equal marginal revenues:

$$
\begin{aligned}
G^{\prime}\left(X_{L}\right)+ & \frac{1}{2} \cdot\left[a_{L}+C^{\prime}\left(\frac{Q\left(a_{L}, X_{L}\right)}{2}\right)\right] \cdot \frac{\partial Q}{\partial X_{L}}= \\
& a_{L} \cdot \frac{\partial Q}{\partial X_{L}}+\frac{1}{2} \cdot\left[(1-t) \cdot\left[P\left(Q\left(a_{L}, X_{L}\right)\right)+P^{\prime}\left(Q\left(a_{L}, X_{L}\right)\right) \cdot Q\left(a_{L}, X_{L}\right)\right]\right] \cdot \frac{\partial Q}{\partial X_{L}}
\end{aligned}
$$

Marginal costs comprise the monopolist's expenses for constructing and maintaining one more network unit and the costs the affiliated generator incurs for supplying half an additional electricity unit (consisting of both the generating costs and the aquisition expenditure for the grid capacity essential for dispatching). Marginal revenues include the access fee the downstream generators pay when they purchase the incremental network unit and the affiliate's earnings (i.e., the net market price) for half an additional electricity unit reduced by the net price decrease for its inframarginal power units. Except for the marginal construction costs that occur as soon as the incremental capacity is installed, all marginal costs and revenues arise only when the additional grid unit is employed by the downstream duopolists, i.e. when $\frac{\partial Q}{\partial X_{L}}=1$. This is the case when the network size prevents the generators to produce their unconstrained Cournot equilibrium outputs, i.e. when $X_{L}<Q^{*}\left(a_{L}\right)$ (see (4)); by applying the left derivative of the $Q\left(a_{L}, X_{L}\right)$-function at its kink point here and in the following, we furthermore assume the duopolists to purchase the marginal capacity also when $X_{L}=Q^{*}\left(a_{L}\right)$.

We complete our discussion of (7) by shifting attention to the price reduction for the affiliate's inframarginal electricity units. The lowering of the power price is an aggregated effect that has two different origins: it results from the half-a-unit increases in the electricity outputs of both the affiliated and the competing generator following the one-unit increase in the network capacity. This can be illustrated by rewriting the legally separated monopolist's first-order condition as ${ }^{8}$

\footnotetext{
${ }^{8}$ Due to space restrictions, we refrain from mentioning the arguments of $Q\left(a_{L}, X_{L}\right)$ in (8).
} 


$$
\begin{aligned}
\frac{\partial \pi_{v}}{\partial X_{L}}=a_{L} & \cdot \frac{\partial Q}{\partial X_{L}}-G^{\prime}\left(X_{L}\right) \\
& +\underbrace{\frac{1}{2} \cdot\left[(1-t) \cdot\left[P(Q)+P^{\prime}(Q) \cdot \frac{Q}{2}\right]-a_{L}-C^{\prime}\left(\frac{Q}{2}\right)\right] \cdot \frac{\partial Q}{\partial X_{L}}}_{\frac{\partial \pi_{1}}{\partial q_{1}}} \\
& +\underbrace{\stackrel{!}{=}}_{\frac{\partial \pi_{2}}{2} \cdot\left[(1-t) \cdot P^{\prime}(Q) \cdot \frac{Q}{2}\right] \cdot \frac{\partial Q}{\partial X_{L}}} 0
\end{aligned}
$$

(recall that $q_{1}\left(a_{L}\right)=q_{2}\left(a_{L}\right)=\frac{Q\left(a_{L}, X_{L}\right)}{2}$ due to the duopolists' identity). The second line of (8) describes the marginal effect the half-a-unit increase in the affiliate's power production has on its profits. But as an identically sized rise in the competitor's generation is induced by the capacity expansion, the monopolist also has to take account of the marginal effect the competing generator's production decision has on the affiliate's profits: it further lowers the price for inframarginal electricity units (see the third line of (8)). The incremental grid unit hence allows the affiliated generator to raise downstream profits by dispatching half an additional electricity unit, but at the same time it causes a $\underline{d}$ ouble $\underline{r}$ eduction $\underline{o f} \underline{p r i c e s}$; henceforth, we will therefore refer to the competitor-induced power price decrease as the $\underline{d r o p}$-effect of the network expansion.

We now draw on (8) to illustrate the effect of a one-unit increase in the grid size on the legally unbundled utility's total profits. Differentiating between the cases where the network size $X_{L}$ is greater than, equal to and smaller than the total unconstrained Cournot output in the downstream market, $Q^{*}\left(a_{L}\right)$, we get

$$
\begin{aligned}
& \left.\frac{\partial \pi_{v}}{\partial X_{L}}\right|_{X_{L}>Q^{*}\left(a_{O}\right)}=-G^{\prime}\left(X_{L}\right)<0, \\
& \left.\frac{\partial \pi_{v}}{\partial X_{L}}\right|_{X_{L}=Q^{*}\left(a_{L}\right)}=a_{L}-G^{\prime}\left(Q^{*}\left(a_{L}\right)\right)+\frac{1}{2} \cdot P^{\prime}\left(Q^{*}\left(a_{L}\right)\right) \cdot \frac{Q^{*}\left(a_{L}\right)}{2},
\end{aligned}
$$

and

$$
\begin{aligned}
\left.\frac{\partial \pi_{v}}{\partial X_{L}}\right|_{X_{L}<Q^{*}\left(a_{L}\right)}= & a_{L}-G^{\prime}\left(X_{L}\right) \\
& +\frac{1}{2} \cdot\left[(1-t) \cdot\left[P\left(X_{L}\right)+P^{\prime}\left(X_{L}\right) \cdot X_{L}\right]-a_{L}-C^{\prime}\left(\frac{X_{L}}{2}\right)\right] .
\end{aligned}
$$


When the grid capacity exceeds the aggregate unconstrained power production, $X_{L}>$ $Q^{*}\left(a_{L}\right)$, only the marginal upstream costs occur: neither generator dispatches more electricity than its Cournot amount, so that all additional network units which expand the grid beyond $Q^{*}\left(a_{O}\right)$ remain unused. Accordingly, the downstream affiliate does not incur any marginal costs, nor does it generate marginal revenues. The grid company, moreover, lacks purchasers for the overcapacity and hence gets no income via the usage charge for all excess units; instead, these parts of the network produce marginal losses, since the upstream monopolist is left with its marginal construction costs. Consequently, overcapacity is never installed by the grid company; it would unnecessarily reduce $\pi_{v}$ that the legally unbundled monopolist strives to maximize.

If the network size coincides with $Q^{*}\left(a_{L}\right)$, the duopolists in the last stage choose their profit-maximizing production levels. The downstream marginal costs and marginal revenues the affiliate allows for when it takes its production decision then cancel out of the third stage first-order condition and the grid company has to compare its marginal revenues from the access fee with the remaining marginal costs: beyond the grid construction costs for the last unit, these also include the competitor-induced drop-effect.

When a low grid capacity finally prevents the generators from dispatching their unconstrained Cournot outputs, the marginal costs and revenues factored in by the affiliate differ from each other and become hence relevant for upstream decisions as well. Compared to the situation where $X_{L}=Q^{*}\left(a_{L}\right)$ therefore both the marginal downstream costs beyond the drop-effect and all marginal downstream revenues enter the third stage optimization problem.

Whether it is optimal for the legally unbundled monopolist to choose the network size equal to or smaller than the sum of the generator's unconstrained Cournot outputs depends on the marginal effect the $Q^{*}\left(a_{L}\right)$-th unit has on overall profits:

Result 1: Suppose that $\pi_{v}$ is strictly concave in $X_{L}$ and define $\Lambda\left(a_{L}\right):=$ $a_{L}-G^{\prime}\left(Q^{*}\left(a_{L}\right)\right)+\frac{1}{2} \cdot(1-t) \cdot P^{\prime}\left(Q^{*}\left(a_{L}\right)\right) \cdot \frac{Q^{*}\left(a_{L}\right)}{2}$. Then,

$$
X_{L}^{*}\left(a_{L}\right) \begin{cases}=Q^{*}\left(a_{L}\right) & \text { if } \Lambda\left(a_{L}\right) \geq 0 \\ <Q^{*}\left(a_{L}\right) \text { and } X_{L}^{*}\left(a_{L}\right) \text { solves } \frac{\partial \pi_{v}}{\partial X_{L}}=0 & \text { if } \Lambda\left(a_{L}\right)<0\end{cases}
$$

Two different cases exist in which it is optimal for the upstream firm to provide a grid capacity equal to $Q^{*}\left(a_{L}\right)$ : the first one occurs when the provision of the $Q^{*}\left(a_{L}\right)$-th unit has a positive marginal effect on aggregated upstream and downstream profits, i.e. when the access fee from selling one more network unit exceeds the sum of its construction costs and the drop-effect. In this case, the grid size undercuts the capacity that maximizes the overall profits, but the lacking downstream demand for still more capacity prevents the legally unbundled monopolist 
from further expanding the network. The second case arises when the marginal revenues and the marginal costs that remain to be considered by the grid company when the affilated generator produces its profit-maximizing output just cancel out. The number of grid units that lets the monopolist reach the maximum of $\pi_{v}$ is then exactly twice as much as the amount of power the downstream affiliate dispatches to reach its own profit function's maximum and both the third and the fourth stage optimality condition are simultaneously fulfilled.

As soon as providing the $Q^{*}\left(a_{L}\right)$-th network unit affects aggregated profits negatively, the legally unbundled monopolist cuts back capacity below the total of the duopolists' unconstrained Cournot outputs: this happens when the usage charge does not cover both the marginal construction costs and the drop-effect. In this case, a capacity of $Q^{*}\left(a_{L}\right)$ would prevent the grid company from maximizing $\pi_{v}$ since the optimal network size would be exceeded; to maximize aggregated profits, capacity is therfore curtailed by the monopolist until only $X_{L}^{*}\left(a_{L}\right)$ grid units are supplied.

As the regulator uses the access charge (together with the type of unbundling that is implemented) to optimally achieve its respective regulatory objective, we finally analyze the effect of a marginal increase in the network fee on the grid capacity. Depending on whether the network size constrains the dispatch of electricity or not, the capacity change resulting from a one-unit increase in the access fee differs:

$$
\begin{array}{lr}
\frac{\partial X_{L}}{\partial a_{L}}=\frac{\partial Q^{*}\left(a_{L}\right)}{\partial a_{L}}<0 & \text { for } \Lambda\left(a_{L}\right)>0 \\
\frac{\partial X_{L}}{\partial a_{L}}=-\frac{\frac{1}{2}}{-G^{\prime \prime}\left(X_{L}\right)+(1-t) \cdot\left[P^{\prime}\left(X_{L}\right)+P^{\prime \prime}\left(X_{L}\right) \cdot \frac{X_{L}}{2}\right]-\frac{1}{4} \cdot C^{\prime \prime}\left(\frac{X_{L}}{2}\right)}>0 & \text { for } \Lambda\left(a_{L}\right)<0 .
\end{array}
$$

As long as the grid size and the sum of the generators' unconstrained Cournot equilibrium outputs do not differ since the capacity demanded by the duopolists is smaller than the network size that maximizes the legally unbundled utility's total profits $\pi_{v}$, the reaction of the aggregated generation to small increases in $a_{L}$ is decisive for the adjustment of the grid size: in this case, the monopolist's possibility to sell network units depends entirely on the generators' willingness to buy them. Since a higher access fee (and thus an increase in the marginal production costs) results in a reduction in the downstream demand for capacity (see (5) and Appendix A1), the grid company will lower the network size to avoid the provision of redundant and hence lossgenerating grid units.

When the duopolists' aggregated profit-maximizing electricity amounts and the network size maximizing the legally unbundled utility's profits coincide (i.e. for $\Lambda=0$ ), the capacity change due to a marginal increase in the access fee cannot be determined; the derivative is not defined at the kink point of the $Q\left(a_{L}, X_{L}\right)$-function (see Section 3.1). 
Whenever the generators would like to dispatch more electricity than the existing capacity allows, the monopolist will expand the grid when the usage fee is raised to take advantage of the downstream demand for additional network units: purchasing them will allow the generators to produce electricity amounts closer to their profit-maximizing outputs (which will be slightly reduced by a small increase in $a_{L}$, but not in a way that the added capacity remains unused). Satisfying the additional downstream demand after a fee increase is the monopolist's optimal decision, as the application of the implicit function theorem to the legally unbundled utility's first-order condition shows: the denominator of the second fraction in (9) equals the second derivative of the legally unbundled utility's profit function with respect to the capacity at points where $X_{L}<Q^{*}\left(a_{L}\right)$; this has to be negative to let $X_{L}^{*}$ denote a (local) maximum, so that the network is expanded whenever the grid size prevents the generators from dispatching their unconstrained Cournot outputs.

\subsubsection{Ownership Unbundling}

When Ownership instead of Legal Unbundling is implemented, the upstream monopolist does not have any incentive to influence competition in the downstream market since an affiliated generator which might benefit from a suboptimal grid expansion no longer exists. Accordingly, the grid company does not take account of any downstream marginal costs or revenues and solves the maximization problem

$$
\max _{X_{O}^{*}} \pi_{n}\left(X_{O}\right)=a_{O} \cdot Q\left(a_{O}, X_{O}\right)-G\left(X_{O}\right),
$$

where $\pi_{n}$ denotes the entirely unbundled monopolist's profits and $X_{O}$ the network capacity the grid company provides. As in 3.2.1, we draw on the monopolist's first-order condition,

$$
\frac{\partial \pi_{n}}{\partial X_{O}}=a_{O} \cdot \frac{\partial Q}{\partial X_{O}}-G^{\prime}\left(X_{O}\right) \stackrel{!}{=} 0
$$

at points where the network size is greater than, equal to and smaller than the sum of the generators' unconstrained Cournot outputs $Q^{*}\left(a_{O}\right)$ to analyze the effect of a marginal capacity

increase on the grid company's profits. To substitute $\frac{\partial Q}{\partial X_{O}}$, we use (4) and apply the left derivative of the $Q\left(a_{O}, X_{O}\right)$-function at its kink. This gives

$$
\begin{aligned}
& \left.\frac{\partial \pi_{n}}{\partial X_{O}}\right|_{X_{O}>Q^{*}\left(a_{O}\right)}=-G^{\prime}\left(X_{O}\right)<0, \\
& \left.\frac{\partial \pi_{n}}{\partial X_{O}}\right|_{X_{O}=Q^{*}\left(a_{O}\right)}=a_{O}-G^{\prime}\left(Q^{*}\left(a_{O}\right)\right),
\end{aligned}
$$


and

$$
\left.\frac{\partial \pi_{n}}{\partial X_{O}}\right|_{X_{O}<Q^{*}\left(a_{O}\right)}=a_{O}-G^{\prime}\left(X_{O}\right) .
$$

As in the case of Legal Unbundling, grid units exceeding the duopolists' aggregated unconstrained Cournot output are not installed as they reduce upstream profits: they lead to marginal costs, but do no generate marginal revenues. When the network size coincides with $Q^{*}\left(a_{O}\right)$ or undercuts it, respectively, the grid company earns the access fee for supplying the marginal unit and incurs its marginal construction costs.

Whether it is optimal for the entirely separated, profit-maximizing monopolist to provide a capacity equal to or smaller than $Q^{*}\left(a_{O}\right)$ is described in

Result 2: Define $\Omega\left(a_{O}\right):=a_{O}-G^{\prime}\left(Q^{*}\left(a_{O}\right)\right)$. Then,

$$
X_{O}^{*}\left(a_{O}\right) \begin{cases}=Q^{*}\left(a_{O}\right) & \text { if } \Omega\left(a_{O}\right) \geq 0 \\ <Q^{*}\left(a_{O}\right) \text { and } X_{O}^{*}\left(a_{O}\right) \text { solves } \frac{\partial \pi_{n}}{\partial X_{O}}=0 & \text { if } \Omega\left(a_{O}\right)<0 .\end{cases}
$$

Under Ownership Unbundling, it is hence optimal for the grid company to completely satisfy the downstream demand for capacity when the usage charge is higher than or equal to the marginal costs for providing the $Q^{*}\left(a_{O}\right)$-th network unit; in these cases, the grid size that maximizes $\pi_{n}$ exceeds the aggregated power production that maximizes the sum of $\pi_{1}$ and $\pi_{2}$ or coincides with it, respectively. If, on the contrary, the $Q^{*}(a)$-th unit's marginal effect on upstream profits is negative, the monopolist reduces capacity below the total of the generators' unconstrained Cournot outputs and chooses a network size where the marginal unit's construction costs equal the access fee to realize maximum profits.

The linkage between total downstream capacity demand and optimal network size is also reflected in the capacity changes that are induced by small increases in the usage charge:

$$
\begin{array}{ll}
\frac{\partial X_{O}}{\partial a_{O}}=\frac{\partial Q^{*}\left(a_{O}\right)}{\partial a_{O}}<0 & \text { for } \Omega\left(a_{O}\right)>0 \\
\frac{\partial X_{O}}{\partial a_{O}}=\frac{1}{G^{\prime \prime}\left(X_{O}\right)}>0 & \text { for } \Omega\left(a_{O}\right)<0 .
\end{array}
$$

Whenever the duopolists' demand for network units constrains the grid size, the reaction of the generators' aggregated unconstrained Cournot output determines the change in network size: since an increase in $a_{O}$ leads to a lower $Q^{*}\left(a_{O}\right)$ (see $(5)$ and Appendix A1), the monopolist will downsize the grid. If, conversely, a network capacity undercutting $Q^{*}\left(a_{O}\right)$ constrains the 
dispatch of power, the demand for network units will exceed its supply also in case of a slightly higher usage charge. Applying the implicit function theorem to the grid company's first-order condition to identify the impact of a one-unit raise of $a_{O}$ on the network size then reveals an increase in capacity to be optimal. For $X_{O}^{*}\left(a_{O}\right)=Q^{*}\left(a_{O}\right)$ (i.e for $\Omega=0$ ) the optimal change in network size cannot be determined as the derivative is not defined at the kink of the $Q\left(a_{O}, X_{O}\right)$ function (see Section 3.1).

\subsubsection{Comparisons}

Based on the results from Sections 3.2.1 and 3.2.2 we now compare the two types of unbundling.

First, we draw on Results 1 and 2 which define the thresholds that determine when the optimal size of a legally or an entirely separated network, respectively, satisfies the duopolists' total capacity demand. Together, the Results allow us to identify when the optimal grid sizes under both regulatory regimes correspond to the generators' unconstrained aggregated Cournot outputs (and are therefore identical) when a uniform usage charge $a$ is set under both types of unbundling:

(a) Suppose $\Lambda(a) \geq 0$; then, $\Omega(a)>0$. That is, whenever $X_{L}^{*}(a)=Q^{*}(a)$, then $X_{O}^{*}(a)=Q^{*}(a)$, too.

Note that $\Lambda(a)=\Omega(a)+\frac{1}{2} \cdot(1-t) \cdot P^{\prime}\left(Q^{*}(a)\right) \cdot \frac{Q^{*}(a)}{2}<\Omega(a)$ for every access fee: due to the drop-effect a legally unbundled grid company takes into account in contrast to an entirely separated one, the marginal costs for providing the $Q^{*}(a)$-th network unit are always higher for an upstream monopolist under Legal Unbundling.

Accordingly, with identical grid charges under Legal and Ownership Unbundling, $a_{L}=a_{O}$, it is optimal for an entirely separated grid company to provide a capacity equal to the sum of the generators' unconstrained Cournot outputs whenever it is optimal to do so for a legally unbundled monopolist. $\Lambda(a) \geq 0$ implies that the legally unbundled grid company's marginal costs do not exceed its marginal revenues at $X_{L}=Q^{*}(a)$; then, the even lower marginal costs a grid company unbundled by ownership incurs if it provides $Q^{*}(a)$ will undercut the (identical) marginal revenues as well, and installing a network that accommodates the entire downstream capacity demand maximizes the entirely separated monopolist's profits.

Results 1 and 2 furthermore enable us to determine when the optimal capacities under both types of unbundling differ from the total amount of electricity the duopolists would like to dispatch when an identical access fee $a$ is licensed under both regulatory regimes:

(b) Suppose $\Omega(a) \leq 0$; then, $\Lambda(a)<0$. That is, whenever $X_{O}^{*}(a)<Q^{*}(a)$, then $X_{L}^{*}(a)<Q^{*}(a)$, too. 
For a legally unbundled grid company it is hence optimal to constrain capacity below $Q^{*}(a)$ whenever the profit-maximizing network size of a monopolist separated by ownership is smaller than or equal to the generators' aggregated unconstrained Cournot outputs. In these cases, the marginal revenues the entirely separated grid company earns from providing the $Q^{*}(a)$-th network unit undercut or just cover, respectively, its marginal construction costs; and since in both cases the marginal costs a legally unbundled monopolist incurs are even higher due to the $d r o p$-effect it allows for, maximizing $\pi_{v}$ implies a capacity lower than $Q^{*}(a)$.

Whenever a capacity $X_{L}=Q^{*}(a)$ is suboptimal for the legally unbundled grid company, $X_{L}^{*}(a)$ and $X_{O}^{*}(a)$ differ in all but one case when a uniform fee $a$ is set because of the downstream marginal costs and revenues only the legally separated monopolist takes into account:

Result 3: Define $X_{O}^{*}(a)$ as the solution to $a-G^{\prime}\left(X_{O}\right)=0$ and

$$
\begin{aligned}
\Gamma(a) & :=\left.\frac{\partial \pi_{v}}{\partial X_{L}}\right|_{X_{L}=X_{O}^{*}(a)} \\
& =\frac{1}{2} \cdot\left[(1-t) \cdot\left[P\left(X_{O}^{*}(a)\right)+P^{\prime}\left(X_{O}^{*}(a)\right) \cdot X_{O}^{*}(a)\right]-a-C^{\prime}\left(\frac{X_{O}^{*}(a)}{2}\right)\right]
\end{aligned}
$$

Assume $\pi_{v}$ to be strictly concave in $X_{L}$. Then,

$$
X_{L}^{*}(a) \begin{cases}>X_{O}^{*}(a) & \text { if } \Gamma(a)>0 \\ =X_{O}^{*}(a) & \text { if } \Gamma(a)=0 \\ <X_{O}^{*}(a) & \text { if } \Gamma(a)<0 .\end{cases}
$$

If the legally unbundled grid company installs a capacity equal to $X_{O}^{*}(a)$, the network's marginal revenues $a$ and the marginal construction costs for providing the incremental grid unit cancel out in the optimization problem the legally separated monopolist has to solve whenever $X_{L}<Q^{*}(a)$. If the affiliate's marginal profits (including the drop-effect) associated with the installation of the $X_{O}^{*}(a)$-th grid unit (i.e. $\left.\Gamma(a)\right)$ are then positive, expanding the network is optimal for the legally unbundled grid company.

For such a situation to occur, the demand for electricity has to be price $\operatorname{elastic}^{9}$ : if $\Gamma(a)$ defined in (11) is positive, then rearranging yields

\footnotetext{
${ }^{9}$ See Section 3.1 for empirical examples of countries with an elastic long-run electricity demand. Examples for countries with an inelastic long-run demand - a situation discussed at the end of this section - can be found there as well.
} 


$$
1-\underbrace{\left[\frac{a+C^{\prime}\left(\frac{X_{O}^{*}(a)}{2}\right)}{(1-t) \cdot X_{O}^{*}(a)}\right] \cdot \frac{\partial X_{O}^{*}(a)}{\partial P\left(X_{O}^{*}(a)\right)}}_{>0}<-\frac{P\left(X_{O}^{*}(a)\right)}{X_{O}^{*}(a)} \cdot \frac{\partial X_{O}^{*}(a)}{\partial P\left(X_{O}^{*}(a)\right)},
$$

where the term on the right-hand side of (12) is the price elasticity of demand as defined in (1) at $X_{O}^{*}(a)$, multiplied by minus one. Consequently, to make inequality (12) hold, the elasticity has to be smaller than minus one.

From (12), a price elastic demand also prevails when $\Gamma(a)=0$. In this case, the affiliate's marginal profits from selling half an additional electricity unit and the drop-effect add up to zero; the optimal capacity is then independent of the regulatory regime. Here, the network size is smaller than $Q^{*}(a)$ : with $\Gamma(a)=0$,

$$
\left.\left(\frac{\partial \pi_{1}}{\partial q_{1}}+\frac{\partial \pi_{1}}{\partial q_{2}}\right)\right|_{q_{1}=q_{2}=\frac{X_{O}^{*}(a)}{2}}=0 ;
$$

and since the drop-effect affects the affiliated generator's profits negatively,

$$
\left.\frac{\partial \pi_{1}}{\partial q_{2}}\right|_{q_{1}=q_{2}=\frac{X_{O}^{*}(a)}{2}}<0,
$$

the marginal profits generated by dispatching half another power unit have to be positive,

$$
\left.\frac{\partial \pi_{1}}{\partial q_{1}}\right|_{q_{1}=q_{2}=\frac{x_{O}^{*}(a)}{2}}>0 .
$$

Consequently, the affiliate and thus also its identical competitor would like to expand generation.

If installing a grid of size $X_{O}^{*}(a)$ finally has a negative overall effect on downstream (and hence also on the legally unbundled utility's total) profits, the legally separated monopolist cuts back the size of the network below the entirely separated monopolist's optimal capacity to maximize its profits. This can happen in case of a (less) elastic, a unit elastic or an inelastic electricity demand: consider (12) again; with an elasticity only slightly smaller than minus one, the left-hand side of the inequality might exceed its right-hand side. The inequality then no longer holds with a less-than, but a greater-than sign and $\Gamma(a)$ is negative. Correspondingly, the inequality sign turns with an elasticity equal to minus one or higher. 


\subsubsection{Upstream Capacities and Downstream Generation}

We now outline the relationship between the generators' aggregated unconstrained Cournot outputs and optimal grid sizes under Legal and Ownership Unbundling (see Figure 3). The red curve depicts the downstream duopolists' total Cournot equilibrium production for different access fees, neglecting whether the capacity the generators need to dispatch their production is provided by the upstream monopolist or not. With $Q^{*}(a)$ being reduced by increasing grid charges (see (5) and Appendix A1), the graph is negatively sloped. The purple graph illustrates the profit-maximizing network size of a legally unbundled grid company when network capacity constrains downstream power production below $Q^{*}(a)$, and the blue curve describes an entirely separated monopolist's optimal grid size when generation is constrained. Both the purple and the blue graph are upward-sloping, since higher usage charges call for network expansions as long as the capacity is smaller than $Q^{*}(a)$, as (9) and (10), respectively, show.

We know from (13) and (14) that the capacity that is provided when $\Gamma(a)=0$ is lower than the total electricity amount the generators would like to dispatch when the access fee that entails identical optimal grid sizes under both regulatory regimes is set; accordingly, the point of intersection of the $X_{L}^{*}(a)$ - and the $X_{O}^{*}(a)$-curve lies below the graph for $Q^{*}(a)$. Calculating the derivative of $\Gamma(a)$ with respect to $a$ yields

$$
\frac{\partial \Gamma(a)}{\partial a}=-\frac{1}{2}+\underbrace{\left[\left.\frac{\partial^{2} \pi_{v}}{\partial X_{L}^{2}}\right|_{X_{L}=X_{O}^{*}(a)}\right]}_{<0} \cdot \underbrace{\frac{\partial X_{O}}{\partial a}}_{>0}<0,
$$

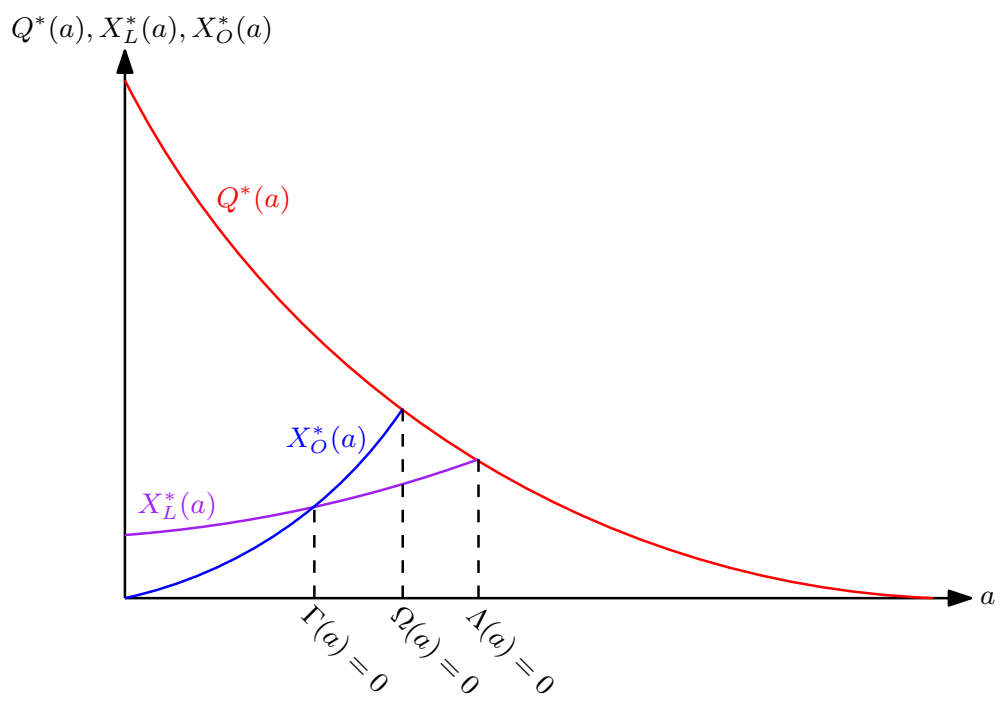

Figure 3: TOTAL DOWNSTREAM CAPACITY DEMAND AND OPTIMAL CAPACITIES UNDER LEGAL AND OWNERSHIP UNBUNDLING 
so that the optimal capacity under Legal Unbundling is higher than the optimal grid size under Ownership Unbundling in case of low access fees (i.e., left of the intersection), whereas it is just the other way round in case of high charges (i.e., right of the intersection). When purchasing network units is cheap, the legally unbundled utility provides a larger grid, since the affiliate's downstream profits (including the $d r o p$-effect) outweigh the profit setbacks or losses that arise in the upstream division when the network size exceeds the capacity that maximizes an entirely separated monopolist's profits (i.e., $X_{O}^{*}(a)$ ). When the grid access gets more expensive, the legally unbundled monopolist refrains from installing a capacity equal to $X_{O}^{*}(a)$, since doing so would result in downstream profit reductions that could not be absorbed by the network's income increases; by providing $X_{L}^{*}(a)$, however, the network generates just enough excess profits to cover the affiliated generator's simultaneous losses. The dominating negative effect on the affiliate's profits that would occur if a capacity equal to $X_{O}^{*}(a)$ was provided originates solely from the drop-effect the legally unbundled monopolist takes into account: as long as $X_{O}^{*}(a) \leq Q^{*}(a)$,

$$
\left.\frac{\partial \pi_{1}}{\partial q_{1}}\right|_{q_{1}=q_{2}=\frac{X_{O}^{*}(a)}{2}} \geq 0 .
$$

Differentiating $\Omega(a)$ gives

$$
\frac{\partial \Omega(a)}{\partial a}=1-\underbrace{G^{\prime \prime}\left(Q^{*}(a)\right)}_{>0} \cdot \underbrace{\frac{\partial Q}{\partial a}}_{<0}>0
$$

suggesting unconstrained Cournot equilibrium outputs of the generators that, in total, exceed the optimal network size of an entirely separated grid when access fees are low. The small price for using the network does not allow for a cost-covering provision of the last $Q^{*}(a)-X_{O}^{*}(a)$ units and hence prevents the monopolist separated by ownership to satisfy the entire downstream demand. In case of higher charges (i.e., those that lead to $\Omega(a)>0$ ), capacity is adapted to total generation (see Result 2).

Basically similar results can be observed for the relation between downstream capacity demand and the optimal grid size of a legally unbundled grid company. The first derivative of $\Lambda(a)$ with respect to $a$ is

$$
\frac{\partial \Lambda(a)}{\partial a}=1+\underbrace{\left[\left.\frac{\partial^{2} \pi_{v}}{\partial X_{L}^{2}}\right|_{X_{L}=Q^{*}(a)}\right]}_{<0} \cdot \underbrace{\frac{\partial Q}{\partial a}}_{<0}>0,
$$


so that a cheap network access leads to a grid capacity smaller than the generators' aggregated unconstrained Cournot outputs also under Legal Unbundling: here, the sum of the fee and the affiliate's marginal profits (including the drop-effect) does not suffice to cover the marginal construction costs for the last $Q^{*}(a)-X_{L}^{*}(a)$ units of the network and the electricity dispatch is limited to $X_{L}^{*}(a)$. For high usage charges (resulting in $\Lambda(a)>0$ ), capacity is again determined by $Q^{*}(a)$ (see Result 1$)$.

\subsection{Interim Summary}

We can briefly summarize the results from Section 3 as follows:

- In case of low access fees (i.e., those that lead to $\Lambda\left(a_{L}\right)<0\left[\Omega\left(a_{O}\right)<0\right]$ ), downstream generation is constrained by the capacity the legally [entirely] separated grid company provides. When usage charges are high (implying $\Lambda\left(a_{L}\right) \geq 0\left[\Omega\left(a_{O}\right) \geq 0\right]$ ), network construction is constrained by the low capacity demand of downstream generators (see Result 1 [Result 2]).

- When generation is constrained by the grid and access fees are slightly raised, capacity (and thus power production) is increased; when downstream capacity demand constrains network construction, a fee increase reduces power production (and thus the grid size) (see (9) $[(10)])$.

- With low [medium] access fees (i.e., those that result in $\Gamma(a)>0[\Gamma(a)<0]$ ), the capacity under Legal Unbundling is higher [lower] than under Ownership Unbundling. There exists one usage charge that implies identical profit-maximizing capacities under both regulatory regimes (and $\Gamma(a)=0$ ) when generation is constrained by the network size (see Result 3 ).

- The larger the network size (and the $\Gamma(a)$-value), the less price elastic is the electricity demand (see the analysis of Result 3).

\section{The Regulatory Authority}

\subsection{The Regulator's Choice of the Access Charge}

Being fully informed about the decisions the downstream generators and the (either legally or entirely separated) upstream monopolist take when a certain network charge is set, the authority licenses the access fee that ensures the achievement of the regulatory objective in the best possible way in the second stage. This choice of the regulator is analyzed and compared for both types of unbundling and the different potential regulatory targets in the following; we draw on the order of objectives introduced in Section 2 during their elucidation to structure the 
analysis. In this section, $a_{L}^{* *}\left[a_{O}^{* *}\right]$ denotes the authority's optimal choice for the usage charge when Legal [Ownership] Unbundling is implemented; the capacity the legally [entirely] separated grid company installs when this charge is set is labeled with $X_{L}^{* *}\left(a_{L}^{* *}\right)\left[X_{O}^{* *}\left(a_{O}^{* *}\right)\right]$.

\subsubsection{Consumer-Oriented Objectives}

Maximizing the electricity dispatch: We know from (9) and (10) that $\frac{\partial X_{L}}{\partial a_{L}}$ and $\frac{\partial X_{O}}{\partial a_{O}}$ are positive [negative] as long as $\Lambda\left(a_{L}\right)$ and $\Omega\left(a_{O}\right)$, respectively, are negative [positive]. For $\Lambda\left(a_{L}\right)=$ 0 and $\Omega\left(a_{O}\right)=0$ (i.e., at the kink points of the $Q(a, X)$-functions), we furthermore apply the right derviative here and in the following, assuming the demand for network units (and hence the capacity provided) to be reduced whenever the access fee is raised and $X_{L}^{*}\left(a_{L}\right)$ and $X_{O}^{*}\left(a_{O}\right)$, respectively, are equal to $Q^{*}\left(a_{L}\right)$ and $Q^{*}\left(a_{O}\right)$, respectively. To maximize the electricity dispatch for a given regulatory regime, the agency hence has to license the access fee that lets the generators' aggregated unconstrained Cournot outputs and the optimal capacity coincide: with $\Lambda\left(a_{L}\right)=0$ and $\Omega\left(a_{O}\right)=0$, every change in $a_{L}$ and $a_{O}$, respectively, reduces the power supply below the maximum possible level. From our findings that $\Lambda(a)<0$ whenever $\Omega(a)=0$ (see Section 3.2.3) and that $\frac{\partial X_{L}}{\partial a_{L}}>0$ if $\Lambda(a)<0$ we can then derive $a_{L}^{* *}>a_{O}^{* *}$ : an authority aiming at a maximum electricity dispatch licenses a higher grid charge when a legally unbundled rather than an entirely separated monopolist constructs the network. Since $\frac{\partial Q^{*}(a)}{\partial a}<0$ (see (5) and Appendix A1), this furthermore implies $X_{L}^{* *}\left(a_{L}^{* *}\right)<X_{O}^{* *}\left(a_{O}^{* *}\right)$ : with the optimal access fee being set in both regulatory environments, the capacity under Legal Unbundling is smaller than under Ownership Unbundling.

Minimizing the power price: Since $P^{\prime}(X)<0$, also this target requires the maximiziation of the electricity dispatch. Licensing the grid charges that lead to $\Lambda\left(a_{L}\right)=0$ and $\Omega\left(a_{O}\right)=0$, respectively, are hence again the optimal choices of the regulator. With both the fees that are set under Legal and Ownership Unbundling and the resulting capacities being identical with those that are licensed and installed, respectively, when the agency's objective is a maximized power supply, $a_{L}^{* *}>a_{O}^{* *}$ and $X_{L}^{* *}\left(a_{L}^{* *}\right)<X_{O}^{* *}\left(a_{O}^{* *}\right)$ also hold when the minimum price is sought.

Maximizing consumer surplus: The consumer surplus is defined as

$$
C S(a):=\int_{0}^{X(a)} P(Q) d Q-P(X(a)) \cdot X(a),
$$

i.e., as the sum of the consumers' willingness to pay for all electricity units supplied minus the total expenditures incurred to buy them. Then, 


$$
\frac{\partial C S(a)}{\partial a}=\underbrace{-P^{\prime}(X(a)) \cdot X(a)}_{>0} \cdot \underbrace{\frac{\partial X}{\partial a}}_{\gtrless 0} .
$$

Since, according to (9) and (10) (and due to the application of the right derivative for $\Lambda\left(a_{L}\right)=0$ and $\left.\Omega\left(a_{O}\right)=0\right), \frac{\partial X_{L}}{\partial a_{L}}$ and $\frac{\partial X_{O}}{\partial a_{O}}$ are positive [negative] when $\Lambda\left(a_{L}\right)$ and $\Omega\left(a_{O}\right)$, respectively, take [non-]negative values, the derivative is only positive when $\Lambda\left(a_{L}\right)<0$ and $\Omega\left(a_{O}\right)<0$ hold. Increasing the access fee hence affects the consumer surplus positively as long as the additional network units the monopolist is willing to provide when the grid charge is raised are entirely purchased by the generators. Then, the electricity dispatch grows, the price drops and consumers are better off. If, however, the fee is raised further, so that the network size is constrained by the decreasing downstream demand, the power supply is reduced, the price increases and the consumer surplus falls. Maximizing consumer surplus thus again means maximizing electricity dispatch; the optimal usage charges for both types of unbundling and the ensuing capacities the monopolist installs are accordingly independent of which of the two objectives the regulator eventually pursues. Consequently, $a_{L}^{* *}>a_{O}^{* *}$ and $X_{L}^{* *}\left(a_{L}^{* *}\right)<X_{O}^{* *}\left(a_{O}^{* *}\right)$ also result if the agency strives for the highest possible consumer surplus.

For a regulatory authority solely acting in the consumers' interest, we can hence summarize our findings in

Proposition 1: The access charge set by a consumer-oriented regulator under Legal Unbundling will always exceed the fee licensed under Ownership Unbundling. An authority striving for a high power supply, a low electricity price or a high consumer surplus will always be better able to achieve its goal with an entirely separated monopolist.

\subsubsection{Business-Oriented Objectives}

Maximizing upstream profits: Upstream profits under either regulatory regime (denoted by $\pi_{u p}$ in the following) are

$$
\pi_{u p}(a)=a \cdot X(a)-G(X(a))
$$

and vary with the access fee by

$$
\frac{\partial \pi_{u p}(a)}{\partial a}=\underbrace{X(a)}_{>0}+\underbrace{\left[a-G^{\prime}(X(a))\right]}_{\geq 0} \cdot \underbrace{\frac{\partial X}{\partial a}}_{\gtrless 0} .
$$


The additional income the monopolist earns due to the higher usage charge for inframarginal network units is reflected in $X(a)$, which is always positive. The effect the capacity change associated with a fee increase has on upstream profits, though, is ambiguous and depends on the sign of $\Omega(a)$ : the difference between the access charge and the marginal construction costs (i.e., the term in square brackets) is either zero or positive (if the raise in the usage charge induces changes in the network size not only affecting the marginal grid unit). Accordingly, as long as a usage charge implies $\Omega(a)<0$ (and thus $\frac{\partial X}{\partial a}>0$, see (10)), a more expensive grid access always results in higher upstream profits: the additional gains generated by the inframarginal units are either not reduced (if the network is only expanded by a single unit, implying marginal construction costs that are just covered by the increased fee) or even further raised (if the incremental capacity is greater than one, therefore yielding positive marginal profits itself).

If, however, $\Omega(a) \geq 0$ (and thus $\frac{\partial X}{\partial a}<0$ ), there is just one single case in which the capacity decrease induced by a higher fee does not diminish the additional income from the inframarginal units: it occurs when $\Omega(a)=0$ and $\frac{\partial X}{\partial a}=-1$, i.e., when only the last grid unit generating zero marginal profits is no longer provided after an increase in $a$. This exception aside, the smaller network always implies that previously profitable grid units can no longer be sold: with $\Omega(a)=0$ and $\frac{\partial X}{\partial a}<-1$, the capacity reduction does not only involve the last unit whose sales revenues just cover its construction costs, but also (a) unit(s) that yield(s) positive marginal profits; with $\Omega(a)>0$, marginal revenues exceed marginal costs for all units that are supplied prior to the fee raise.

While it is hence always optimal for a regulator striving for high upstream profits to further increase the usage charge when $\Omega(a)<0$, it might be suboptimal to do so in case of non-negative $\Omega$-values: whenever the marginal losses from downsizing the grid exceed the additional earnings generated by the inframarginal capacity, marking up the fee will reduce $\pi_{u p}$. To determine the profit-maximizing charge we will therefore make use of the facts that both the fee is a cost component the generators cover by the power price and that its level is independent of this price (see Section 3), and then rearrange (15) so as to be able to base our considerations on our findings on the price elasticity of electricity demand (see Result 3 and its analysis).

First, let $P^{-}(X)$ denote the part of the gross market price for electricity $P(X)$ that is left when usage charge $a$ is subtracted from $P(X)$. We can then rewrite $\frac{a}{X(a)} \cdot \frac{\partial X(a)}{\partial a}$ as

$$
\begin{aligned}
\frac{P(X)-P^{-}(X)}{X\left(P^{-}(X)\right)} \cdot & \frac{\partial X\left(P^{-}(X)\right)}{\partial P^{-}(X)}= \\
& \frac{P(X)}{X\left(P^{-}(X)\right)} \cdot \frac{\partial X\left(P^{-}(X)\right)}{\partial P^{-}(X)}-\frac{P^{-}(X)}{X\left(P^{-}(X)\right)} \cdot \frac{\partial X\left(P^{-}(X)\right)}{\partial P^{-}(X)} .
\end{aligned}
$$


Furthermore, suppose (15) to be greater than zero, implying the marginal effect of a fee increase to be positive. For $\Omega(a) \geq 0$, rearranging then yields

$$
1+\frac{a}{X(a)} \cdot \frac{\partial X(a)}{\partial a}>\underbrace{\frac{G^{\prime}(X(a))}{X(a)}}_{>0} \cdot \underbrace{\frac{\partial X(a)}{\partial a}}_{<0} .
$$

Finally substituting the right-hand side of (16) into (17) gives

$$
1+\frac{P(X)}{X\left(P^{-}(X)\right)} \cdot \frac{\partial X\left(P^{-}(X)\right)}{\partial P^{-}(X)} \underbrace{-\frac{P^{-}(X)}{X\left(P^{-}(X)\right)} \cdot \frac{\partial X\left(P^{-}(X)\right)}{\partial P^{-}(X)}}_{>0}>\underbrace{\frac{G^{\prime}(X(a))}{X(a)}}_{>0} \cdot \underbrace{\frac{\partial X(a)}{\partial a}}_{<0} .
$$

Inequality (18) holds as long as the electricity demand is inelastic or unit-elastic: in these cases, the left-hand side is positive. That is, for medium-high $a$-s (those not much higher than the fees yielding $\Omega(a)=0$ ), a marginal increase in the access charge leads to higher upstream profits. The consumers' minor reaction to price increases in this area lets the additional income from inframarginal grid units outweigh the revenue losses induced by the decrease in power consumption. A further raise in the usage fee then leads to a further reduction in the network size, which, in turn, is associated with a more and more elastic demand. In the end, an authority aiming at maximized grid profits will choose the charge that entails an elasticity (smaller than minus one) exactly equating the left- and the right-hand side of (18), corresponding to an identity of marginal costs and marginal revenues of the fee increase. A precise identification of the usage charge to be chosen is hence not possible within the scope of our model; nevertheless, we can conclude that the optimal fees do not differ between the regulatory regimes, $a_{L}^{* *}=a_{O}^{* *}$, and that the resulting identical market equilibria $\left(X_{L}^{* *}\left(a_{L}^{* *}\right)=X_{O}^{* *}\left(a_{O}^{* *}\right)\right)$ lie on the downward-sloping part of the $Q(a, X)$-curves.

Maximizing downstream profits: The downstream generators' overall profits (labeled by $\pi_{\text {down }}$ in the following) are

$$
\pi_{\text {down }}(a)=(1-t) \cdot P(X(a)) \cdot X(a)-a \cdot X(a)-2 \cdot C\left(\frac{X(a)}{2}\right),
$$

and a higher usage charge alters them by

$$
\frac{\partial \pi_{\text {down }}(a)}{\partial a}=\underbrace{-X(a)}_{<0}+\underbrace{\left[(1-t) \cdot\left[P(X(a))+P^{\prime}(X(a)) \cdot X(a)\right]-a-C^{\prime}\left(\frac{X(a)}{2}\right)\right]}_{\gtrless 0} \cdot \underbrace{\frac{\partial X}{\partial a}}_{\gtrless 0} .
$$


The higher costs for dispatching the inframarginal units always reduce the duopolists' income by $X(a)$. The effect of the marginal unit(s) on total downstream profits is positive [negative] whenever the sum of both marginal revenues and marginal costs that are relevant for the generators' production decision reduced by the drop-effect (i.e., the term in the outer square brackets in (19)) is positive [negative] and $\frac{\partial X}{\partial a}>0$ (i.e., when $\Lambda\left(a_{L}\right)<0$ and $\Omega\left(a_{O}\right)<0$, see (9) and (10), respectively); if $\frac{\partial X}{\partial a}<0$ (and $\Lambda\left(a_{L}\right)$ and $\Omega\left(a_{O}\right)$ are non-negative), $\pi_{\text {down }}$ is increased [decreased] when units generating marginal losses [profits] (implying a negative [positive] term in the outer square brackets in (19)) are no longer dispatched.

It is optimal for an authority aiming at the high overall downstream profits to choose the access fee that leads to $\Gamma(a)=0$. This holds independent of the type of unbundling (see Appendix A2 for a proof), so that $a_{L}^{* *}=a_{O}^{* *}$ and $X_{L}^{* *}\left(a_{L}^{* *}\right)=X_{O}^{* *}\left(a_{O}^{* *}\right)$ when the regulator strictly acts in the interest of the generators.

For a regulator taking decisions only in the industry's interest, the results can be summarized in

Proposition 2: The access charge set by a regulator pursuing business-oriented objectives is identical under Legal and Ownership Unbundling. An authority aiming at high upstream or downstream profits will always be able to reach its goal in the best possible way under both types of vertical separation.

\subsubsection{Government-Oriented Objectives}

Maximizing revenues from electricity taxation: The overall tax yield is the product of the rate and the tax base, which is obtained by multiplying the gross price per power unit with the grid capacity:

$$
T A X(a)=t \cdot P(X(a)) \cdot X(a)
$$

With the tax rate $t>0$ being determined exogenously, the regulator's only possiblity to affect the level of tax revenues is by influencing the network size via the access charge (which, of course, also alters the electicity price and hence the tax yield per unit). The change in the tax receipts resulting from a marginal increase in $a$ is

$$
\frac{\partial T A X(a)}{\partial a}=t \cdot \underbrace{\left[P(X(a))+P^{\prime}(X(a)) \cdot X(a)\right]}_{\gtreqless 0} \cdot \underbrace{\frac{\partial X}{\partial a}}_{\gtrless 0}
$$


The network size increases whenever $\Lambda\left(a_{L}\right)$ and $\Omega\left(a_{O}\right)$, respectively, are smaller than zero (see (9) and (10), respectively). But since the downstream duopolists do not take account of the overall price reduction additional grid capacity induces and consider only how their own increase in generation by half a unit affects the price, the pre-tax marginal revenues of the $X(a)$-th unit might also be zero or negative.

Result 3 and its analysis (especially the findings on a decreasing price elasticity of demand in case of an increasing capacity), though, allow us to draw some conclusions on the effects a raise in the access charge has on the income from electricity taxation: as long as the fee results in non-negative $\Gamma(a)$-values (see (11)), the after-and thus also the pre-tax revenues generated by additional network units have to be positive and the tax yields increase, too. When the price for the grid usage is then further raised, the (continuous) price elasticity of demand decreases more and more, until finally the fee is reached where the network size is associated with a unit-elastic electricity demand. At this point, the term in the square brackets in (20) becomes zero and the tax revenues no longer increase. With any further mark-up on the grid charge, demand becomes inelastic and income from taxation even drops again. To maximize revenues from electricity taxation, the regulator accordingly has to choose the fee that results in a capacity entailing an elasticity of exactly one. This is true independent of the regulatory regime, so that $X_{L}^{* *}\left(a_{L}^{* *}\right)=X_{O}^{* *}\left(a_{O}^{* *}\right)$. However, the access charge necessary to induce such a network size under Ownership Unbundling implies a negative $\Gamma(a)$-value of $\frac{1}{2} \cdot\left[-a_{O}^{* *}-C^{\prime}\left(\frac{X_{O}^{* *}\left(a_{O}^{* *}\right)}{2}\right)\right]^{10}$ and thus a lower capacity under Legal Unbundling; with a legally separated grid, the optimal fee hence has to be higher than with an entirely separated one, $a_{L}^{* *}>a_{O}^{* *}$.

These considerations hold as long as $\Lambda\left(a_{L}\right)$ (see Result 1) and $\Omega\left(a_{O}\right)$ (see Result 2), respectively, are negative. As soon as the maxima of the $Q(a, X)$-curves are reached and higher usage charges lead to a downsizing of the network under both types of unbundling (i.e., when $X_{L}^{*}\left(a_{L}\right)$ and $X_{O}^{*}\left(a_{O}\right)$, respectively, are determined by $Q^{*}(a)$; see Figure 3$)$, tax yields initially grow again: the high capacities right of the maxima are, as mentioned above, associated with an inelastic demand and hence a negative value of the term in the square brackets in (20). Since $\frac{\partial X}{\partial a}<0$ for high fees (see (9) and (10), respectively), the income from electricity taxation consequently rises at the beginning. However, with higher and higher usage charges, the grid size is more and more reduced; this implies an increasing price elasticity until finally electricity demand is unit-elastic again and the marginal effect of a fee increase on tax revenues is zero. Raising the usage charge even further then would result in an elastic demand and hence decreasing tax yields (as the term in the square brackets in (20) turns positive). The maximum income from electricity taxation can accordingly also be realized with high access fees: the optimal capacities $X_{L}^{* *}\left(a_{L}^{* *}\right)=X_{O}^{* *}\left(a_{O}^{* *}\right)$ do not differ from those identified above for negative values of $\Lambda\left(a_{L}\right)$ and

\footnotetext{
${ }^{10}$ With a unit-elastic electricity demand $P\left(X_{O}^{* *}\left(a_{O}^{* *}\right)\right)+P^{\prime}\left(X_{O}^{* *}\left(a_{O}^{* *}\right)\right) \cdot X_{O}^{* *}\left(a_{O}^{* *}\right)$ disappears from the $\Gamma(a)$-term defined in (11) and the mentioned term remains.
} 
$\Omega\left(a_{O}\right)$, but the usage charge/capacity-combinations that are realized now lie on the downwardsloping part of the $Q(a, X)$-curves; the fees under both regulatory regimes are identical in this case, $a_{L}^{* *}=a_{O}^{* *}$.

For an agency focusing on the achievement of its government-oriented goal, we can thus summarize our findings in

Proposition 3: The access charge set by a regulator striving for high revenues from electricity taxation might be higher under Legal than under Ownership Unbundling; the grid capacity, though, is not affected by the level of the usage fee and, independent of the type of unbundling, always identical. An authority interested in high tax yields will thus always be able to reach its target in the best possible way under both regulatory regimes.

\subsection{The Optimal Regulatory Regime}

Based on the results stated in Propositions 1 to 3 we can now derive the regulator's optimal first stage decision on the degree of vertical separation and formulate

Corollary 1: A regulator striving for a high power supply, a low electricity price or a high consumer surplus will mandate Ownership Unbundling.

A network separated by ownership together with the optimal usage charge for this regime, $a_{O}^{* *}$, results in a grid capacity exceeding the highest possible one under Legal Unbundling, as has already been shown above. This allows authorities solely acting in the consumers' interest to better achieve its respective objective.

Furthermore, we get

Corollary 2: A regulator aiming at high upstream or downstream profits or high revenues from electricity taxation is indifferent between Legal and Ownership Unbundling.

That is, the degree of vertical separation becomes irrelevant for the authority as soon as it focuses on business-oriented or government-oriented objectives: when the optimal fees $a_{L}^{* *}$ and $a_{O}^{* *}$ are levied for the access to a legally and an entirely separated network, respectively, the grid capacities installed under both types of unbundling are, as analyzed above, identical. Consequently, also the agency's ability to reach its respective goal does not depend on the regulatory regime.

\subsection{Interpretation of the Results and Policy Implications}

It is this irrelevance of the unbundling regime in cases of authorities that strive for high industry profits or high electricity tax revenues that might also cause the adherence of several EU 
member states to Legal Unbundling: when solely the competition-enhancing effects of an entirely unbundled grid are important, the costs that arise from a change from Legal to Ownership Unbundling are considered rather negligible; but as achieving a business-oriented or governmentoriented objective is equally possible for the agency without restructuring the electricity sector, these costs might tip the scales and prevent the realization of entirely separated grids.

With a regulator not focusing on consumer interests, different types of costs might induce the preservation of only legally unbundled electricity utilities: first, the implementation of Ownership Unbundling is expected to result in a facilitation of regulation (OECD, 2001; Mulder and Shestalova, 2006; European Commission, 2007b, 2007c, 2007d; Pollitt, 2008) due to the removal of the network's interest in generation and supply profits and the concomitant discriminatory actions (OECD, 2001; Mulder and Shestalova, 2006; European Commission, 2007a, 2007b, 2007c, 2007d). Actually an advantage, this might be rated negatively by an authority as soon as it is keen to preserve or even increase its importance (Ogus, 2004, ch. 4.4) - which is, according to the OECD/IEA (2001), virtually always the case (a behavior also in line with that expected from self-serving bureaucrats avid for power described by Downs (1967, ch. IX), Niskanen (1968), Peters (1978, ch. 7), Rourke (1984, ch. 4) and Tullock et al. (2002, ch. 5)). With a lower regulatory compexity probably being associated with a decline in the agency's influence as well as staff and resource reductions, it is reasonable to assume that the authority is interested in the ties between transmission and generation/supply to persist.

Furthermore, transaction costs emerging in the course of a statutory split-off of the network division from an integrated utility because of, e.g., necessary contract renegotiations or in-house reorganizations (Mulder and Shestalova, 2006; Pollitt, 2008) might affect the choice on the type of unbundling as well: although most likely not outweighing the concurrent consumer benefits (Pollitt, 2008), they might induce an authority attaching importance only to industrial interests to avoid any structural changes.

Such a willingness to maintain the status quo of an industry-biased agency might also originate from the higher cost of capital expected as a possible consequence of Ownership Unbundling: either due to smaller firm sizes of the stand-alone divisions after full separation (Pollitt, 2008) or since, at least with respect to entirely unbundled generation and supply companies, high risks are no longer offset by a monopolist's low risk as in the case of vertical integration (Mulder and Shestalova, 2006). This would, again, undesirably reduce the unbundled companies' profits.

A regulator's reluctance to entirely separate an already legally unbundled firm might finally result from the higher risk of foreign takeovers a utility's split parts are probably exposed to (Pollitt, 2008). Most likely irrelevant to the authority, especially political pressure might play a decisive role at this point: due to the paramount importance the energy sector has for the production in industrialized countries (Schneider and Jäger, 2003; Domanico, 2007; Karan and Kazdağli, 2011) politicians are expected to clearly favor domestic ownership for national 
electricity (and gas) companies (Domanico, 2007; Belkin, 2008); to ensure the country's security of supply (Barysch et al., 2007), but also to curb the fear of layoffs (Ahearn, 2006) often linked to foreign takeovers and because of lobbying suspected to take place by incumbent owners ${ }^{11}$ (Domanico, 2007).

The aspects regarding transaction costs, higher cost of capital and the desired prevention of foreign takeovers might gain even further relevance in the regulatory decision-making process when the legally separated electricity companies involved are state-owned. In these cases, politicians might perceive utilities primarily as sources of public revenue and might accordingly try to prevent regulations that reduce or even dry up this income flow in their own interest. That such political interferences might indeed affect agency decisions becomes obvious when the ownership structure of transmission firms in countries still adhering to Legal Unbundling is examined more closely: in Bulgaria, the high-tension grid is a $100 \%$ subsidiary of a fully stateowned holding company (European Commission, 2014c), and also in Hungary the network firm is controlled (European Commission, 2014f) by a public (MVM, 2014) parent company. In France, the government holds $84.49 \%$ of the group owning and operating the transmission lines (EDF, 2014), while the Greek state's share in the parent company fully owning (European Commission, 2014g) the country's high-tension network amounts to 51.12\% (PPC, 2014). In Luxembourg, the state and the City of Luxembourg together with various Luxembourgian local governments hold $24.41 \%$ of the grid company in total, whereas $75.43 \%$ are owned by a holding (Creos, 2014); of this holding, in turn, $25.44 \%$ are owned by the state (being the largest shareholder), $10.01 \%$ by a public investment bank and $8.00 \%$ by the the City of Luxembourg (Enovos, 2014). The Cypriot transmission grid, finally, is owned by a so-called "semi-government company"; it is headed by an authority consisting of appointees of the national Council of Ministers and has to follow directives the government is allowed to issue when the general interest of Cyprus is affected (EAC, 2014). Still equipped with such a considerable influence on the electricity sector, politicians in these countries worrying about public revenue might hence have been prone to abuse their persistent powers to inhibit any structural changes that potentially threaten the treasury's income.

After discussing several possibilities for why a business-oriented or government-oriented agency might adhere to Legal Unbundling, we finally want to draw some inferences on potential modifications in the regulator-regulatee and the regulator-state relationship that might prompt such an agency to put its focus back on its genuine responsibility, the protection and promotion of consumer interests. Throughout the paper, we expect a regulatory authority neglecting this task to do so because of its interest in either financial and occupational amenities provided by

\footnotetext{
${ }^{11}$ In line with this suspicion and our considerations, Wilks and Bartle (2002) argue that, instead of trying to influence authorities directly, regulatees rather try to interfere with regulations by inciting politicians to bias agency decisions in the affected companies' favor.
} 
the regulatees or additional, tax-funded appropriations. Successfully inducing a return of the regulator to consumer-oriented objectives hence implies that, on the one hand, the often still prevailing financial dependence of energy agencies on government funds has to be limited as far as possible: resources the authority receives should rather entirely stem from regulated firms (as it is already the case in some, but by far not all EU member states; sometimes not even a partial contribution by the companies exists) and, if this cannot be guaranteed, government appropriations should at least not depend on the current budgetary position of the state; a fixed amount provided regularly over a long-time horizon together with the decoupling of the regulators' salaries from civil servant pay scales (that are normally affected by a country's economic situation as well) might be an appropriate solution. If, however, the financing of the authority by regulatees can be established, it is important to consider that industry payments should be as independent of the firms' profits as possible; otherwise, a similar misguided incentive could develop.

This eventually brings us to the necessary autonomy from regulated companies: to avoid that an authority accepts bribes or bases its decisions on freely provided, but biased information and acts in the interests of regulatees, the implementation of a collusion-proof incentive scheme is indispensable, as Laffont and Tirole's (1991) and Agrell and Gautier's (2010) findings suggest. Put another way, this means that a higher remuneration of regulators and a better resource endowment of agencies is recommended. Measures to reduce the porosity of the revolving door as, e.g., the often existing cooling-off periods previous to posttenure industry employments (Johannsen et al., 2004; CEER, 2005), on the contrary, should be applied rather carfully: as already mentioned, Salant (1995) and Che (1995) show that a more beneficial regulation might be implemented with an open door.

\section{Conclusion}

By analyzing a multi-stage model of electricity market regulation that focuses on agency decisions on network charges and the degree of vertical separation, our paper provides a possible explanation for the adherence of some EU member states to Legal Unbundling: with access fees set optimally under both Legal and Ownership Unbundling, electricity generation and consumer surplus are higher and power prices are lower when the network is separated by ownership; a regulator acting to the benefit of consumers will hence mandate Ownership Unbundling. As soon as an agency is interested in high industry profits or high revenues from electricity taxation, however, neither type of unbundling allows for a better achievement of the regulatory objective; an adherence to Legal Unbundling might then be induced by the regulator's concern to lose importance, transaction costs or the fear of foreign takeovers or higher capital costs for the entirely separated activities. 
These findings illustrate the importance of agency interests and incentives that cannot be reconciled with the regulator's formal mission. Although actually a well-known issue (addressed in particular in the capture literature), authorities potentially focusing on industry or government interests instead of on the benefits of end-users play virtually no role when, e.g., reasons for a delay or even a failure of (steps of) reform are discussed; in the political process, regulators are rather uniformly treated as reputable "advocates of consumers". By clarifying the impact an authority pursuing objectives deviating from its statutory task can have by means of an example from the area of electricity regulation, this paper might therefore raise the awareness for the relevance of properly designed agency incentives for the avoidance of unintended consequences of reform.

Including both the incentives that ensure the authority's focus on consumer well-being and those that cause the regulator to neglect its formal mission into the theoretical framework might also be an interesting possibility for future research. In this respect, the model at hand is parsimonious: it does not contain any remuneration for regulatory activities and also the assumed increase in government appropriations in the wake of higher tax yields is not implemented. Likewise, model elements familiar from the capture literature such as bribes or the regulator's chances for posttenure employment in the industry as well as the wages paid there are missing; we just suppose the agency to benefit from high upstream or downstream profits when it puts its focus on the business-oriented objectives.

Taking account of the different incomes the regulator earns depending on both the goal pursued and the resulting regulation might provide additional insights to better understand the reasons for the adherence of some EU member states to Legal Unbundling. Incorporating, e.g., the agency's budget cuts probably associated with Ownership Unbundling or potential payments regulatees make to the authority to prevent full separation into the model might allow for a possible explanation for why regulators prefer legally unbundled grids within the theoretical framework: whenever agencies act in the interests of companies or the government and our results hint at their indifference between the two types of unbundling, the monetary (dis)incentives the suggested model extensions would capture might make Legal Unbundling become the authority's unique optimal choice. 


\section{Appendix}

\section{Appendix A1:}

If the downstream market is in equilibrium and the duopolists' production is not constrained by the network size, the set of the generators' first order conditions

$$
\begin{aligned}
& \frac{\partial \pi_{1}}{\partial q_{1}}=(1-t) \cdot\left[P(Q)+P^{\prime}(Q) \cdot q_{1}\right]-a-C^{\prime}\left(q_{1}\right)=0 \\
& \frac{\partial \pi_{2}}{\partial q_{2}}=(1-t) \cdot\left[P(Q)+P^{\prime}(Q) \cdot q_{2}\right]-a-C^{\prime}\left(q_{2}\right)=0
\end{aligned}
$$

is fulfilled.

Linearization of (21) then yields

$$
\left.\begin{array}{cc}
(1-t) \cdot\left[2 \cdot P^{\prime}(Q)+P^{\prime \prime}(Q) \cdot q_{1}\right]-C^{\prime \prime}\left(q_{1}\right) & (1-t) \cdot\left[P^{\prime}(Q)+P^{\prime \prime}(Q) \cdot q_{1}\right] \\
(1-t) \cdot\left[P^{\prime}(Q)+P^{\prime \prime}(Q) \cdot q_{2}\right] & (1-t) \cdot\left[2 \cdot P^{\prime}(Q)+P^{\prime \prime}(Q) \cdot q_{2}\right]-C^{\prime \prime}\left(q_{2}\right)
\end{array}\right)
$$

and Cramer's Rule can be applied to obtain the reactions of the power producers' outputs $q_{1}$ and $q_{2}$, respectively, on changes of the access fee $a$ (Simon and Blume, 1994, ch. 15.3). Let $|J|$ denote the Jacobian determinant of (21). We get

$$
\begin{aligned}
& \frac{d q_{1}}{d a}=\frac{1}{|J|} \cdot\left[(1-t) \cdot\left[2 \cdot P^{\prime}(Q)+P^{\prime \prime}(Q) \cdot q_{2}\right]-C^{\prime \prime}\left(q_{2}\right)-(1-t) \cdot\left[P^{\prime}(Q)+P^{\prime \prime}(Q) \cdot q_{1}\right]\right] \\
& \frac{d q_{2}}{d a}=\frac{1}{|J|} \cdot\left[(1-t) \cdot\left[2 \cdot P^{\prime}(Q)+P^{\prime \prime}(Q) \cdot q_{1}\right]-C^{\prime \prime}\left(q_{1}\right)-(1-t) \cdot\left[P^{\prime}(Q)+P^{\prime \prime}(Q) \cdot q_{2}\right]\right]
\end{aligned}
$$

Now recognize that, first, $|J|=\frac{\partial^{2} \pi_{1}}{\partial q_{1}^{2}} \cdot \frac{\partial^{2} \pi_{2}}{\partial q_{2}^{2}}-\frac{\partial^{2} \pi_{1}}{\partial q_{1} \partial q_{2}} \cdot \frac{\partial^{2} \pi_{2}}{\partial q_{1} \partial q_{2}}$ which has to be positive for the Cournot-Nash equilibrium to be asymptotically stable (Fudenberg and Tirole, 1991, ch. 1.2.5), and, second, $q_{1}=q_{2}=q$ in this equilibrium. Equations (23) then simplify to

$$
\frac{d q}{d a}=\underbrace{\frac{1}{|J|}}_{>0} \cdot \underbrace{\left[(1-t) \cdot P^{\prime}(Q)-C^{\prime \prime}(q)\right]}_{<0}<0 .
$$

Since $Q=2 \cdot q, \frac{\partial Q^{*}(a)}{\partial a}<0$ follows immediately from $(24)$. 


\section{Appendix A2:}

First, note that the pagoda-shaped functions describing the actual total electricity generation under Legal and Ownership Unbundling (compare Figure 3) imply that, independent of the regulatory regime, every output level in the downstream market can be realized by two different usage charges. Choosing the higher fee to reach a given output then always means reducing the generators' overall profits: compared to the alternative with the cheaper grid access, the duopolists' total revenues and total generating cost are identical, while dispatching electricity becomes more expensive. A usage charge resulting in $\Lambda\left(a_{L}\right) \geq 0$ and $\Omega\left(a_{O}\right) \geq 0$, respectively, (inducing an equilibrium on the downward-sloping $Q^{*}(a)$-curve) can hence never be optimal for an authority striving for high total downstream profits.

Furthermore, recall from the analysis of Result 3 that, if $\Gamma(a)>0[\Gamma(a)<0]$, the profits of the legally unbundled monopolist's affiliate are raised when it increases [decreases] its power production - a finding that holds analogously for the identical, independent generator. Consequently, to maximize total downstream profits, the access fee implying that neither an expansion nor a reduction of the duopolists' outputs can positively affect their profits has to be implemented: this is the case when marginal revenues (including the drop-effect) equal marginal costs, or, put another way, when $\Gamma(a)=0$. That is, with a regulator focusing on the maximization of $\pi_{\text {down }}$, $a_{L}^{* *}=a_{O}^{* *}$ and $X_{L}^{* *}\left(a_{L}^{* *}\right)=X_{O}^{* *}\left(a_{O}^{* *}\right)$. 


\section{References}

ACER (2014): The Agency, available online: http://www.acer.europa.eu/The_agency/Pages/ default.aspx, February 2014.

AEEG (2014): About Us, available online: http://www.autorita.energia.it/it/inglese/index.htm, February 2014.

Agrell, P. J. and Gautier, A. (2010): A Theory of Soft Capture, CORE Discussion Paper 2010/85, Center for Operations Research and Econometrics, Catholic University of Louvain, December 2010.

Agrell, P. J. and Gautier, A. (2012a): Rethinking Regulatory Capture, CORE Discussion Paper 2012/1, Center for Operations Research and Econometrics, Catholic University of Louvain, January 2012.

Agrell, P. J. and Gautier, A. (2012b): Regulatory Discretion vs. Mechanics: Information Costs and Capture Risks - Paper Presented at the 9th International Conference on the European Energy Market (EEM 12), Florence School of Regulation, 10 - 12 May 2012, mimeo.

Ahearn, R. J. (2006): Europe: Rising Economic Nationalism?, CRS Report for Congress, Congressional Research Service, 6 July 2006.

Albon, R. (2012): International Insights on Design and Process for Better Economic Regulation of Infrastructure - Paper Presented at the First Annual Conference on the Regulation of Infrastructure Industries, Florence School of Regulation, 15 June 2012, Australian Competition and Consumer Commission, Melbourne, Australia, mimeo.

ASAP (2008): The American State Administrators Project - 2008 Reports and Tables, available online: www.auburn.edu/outreach/cgs/ASAP/tables2008.pdf, October 2013.

Bağdigen, M. (2003): An Analysis of Bureaucratic Attitudes towards Budgeting in Turkey, in: Sağbaş, I. and Bağdigen, M. (eds.): Local Government Finance in Turkey, Afyon Kocatepe University Publication No. 57, Afyonkarahisar, Turkey: Z Ajans Afyon, 83-106.

Barysch, K., Tilford, S. and Wanlin, A. (2007): The Lisbon Scorecard VII - Will Globalisation Leave Europe Stranded?, 1 February 2007, London, UK: Centre for European Reform. 
Belkin, P. (2008): The European Union's Energy Security Challenges, CRS Report for Congress, Congressional Research Service, 30 January 2008.

Blais, A. and Dion, S. (1990): Are Bureaucrats Budget Maximizers? The Niskanen Model \& Its Critics, Polity, 22(4), 655-674.

Blázquez, L., Boogen, N. and Filippini, M. (2012): Residental Electricity Demand for Spain: New Empirical Evidence Using Aggregated Data, CEPE Working Paper No. 82, Centre for Energy Policy and Economics, Swiss Federal Institutes of Technology Zurich, February 2012.

BNetzA (2014): Areas of Responsibility - Energy, available online: http://www.bundesnetz agentur.de/cln_1911/EN/General/Bundesnetzagentur/About/Functions/functions_node.html, February 2014.

Bolle, F. and Breitmoser, Y. (2006): On the Allocative Efficiency of Ownership Unbundling, Discussion Paper No. 255, Department of Business Administration and Economics, European University Viadrina Frankfurt (Oder).

Bowling, C. J., Cho, C.-L. and Wright, D. S. (2004): Establishing a Continuum from Minimizing to Maximizing Bureaucrats: State Agency Head Preferences for Governmental Expansion - A Typology of Administrator Growth Postures, 1964-98, Public Administration Review, 64(4), 489-499.

Breyer, S. (1998): Typical Justifications for Regulation, in: Baldwin, R., Scott, C., Hood, C. (eds.): A Reader on Regulation, Oxford, GB and New York, NY, USA: Oxford University Press, 59-92.

Brunekreeft, G., Goto, M., Meyer, R., Maruyama, M. and Hattori, T. (2014): Unbundling of Electricity Transmission System Operators in Germany - An Experience Report, Bremen Energy Working Papers No. 16, Bremen Energy Research, Jacobs University Bremen, March 2014.

Buchan, D. (2007): Crusading Against Vertical Integration, European Energy Review, 1(1), 68-70.

CEER (2005): CEER Regulatory Benchmark Report 2005, Ref: C05-IEB-08-03, Brussels. 
CEER (2014): About the European Energy Regulators, available online: http://www.ceer.eu/ portal/page/portal/EER_HOME/EER_ABOUT/CEER, February 2014.

CER (2014): Introduction to CER, available online: http://www.cer.ie/about-cer/ cer-organisational-overview, February 2014.

Che, Y.-K. (1995): Revolving Doors and the Optimal Tolerance for Agency Collusion, Rand Journal of Economics, 26(3), 378-397.

Christopoulos, D. K. (2000): The Demand for Energy in Greek Manufacturing, Energy Economics, 22(5), 569-586.

CNMC (2014): Regarding Energy (in Spanish), available online: http://www.cnmc.es/ es-es/energía/sobreenergía.aspx, February 2014.

Cremer, H. and De Donder, P. (2013): Network Investment under Legal and Ownership Unbundling, Review of Network Economics, 12(1), 27-59.

Creos (2014): A Portrait of Creos Luxembourg S.A. (in French), available online: http:// www.creos-net.lu/index.php?id=242, April 2014.

Decker, C. (2010): The Objectives of Economic Regulators: Old Tensions and New Challenges, Issue 36, 29 June 2010, 1-7.

de Hauteclocque, A. and Ahner, N. (2012): 'Opt-Out' Clauses for EU Energy Islands in the Third Liberalization Package: Striking Balances?, EUI Working Paper, RSCAS 2012/71, Robert Schuman Centre for Advanced Studies, European University Institute, December 2012.

Demsetz, H. (1968): Why Regulate Utilities?, Journal of Law and Economics, 11(1), 55-65.

Dicembrino, C. and Trovato, G. (2013): Structural Breaks, Price and Income Elasticity and Forecast of the Monthly Italian Electricity Demand - Paper Presented at the 10th International Conference on the European Energy Market (EEM 13), Royal Institute of Technology (KTH) Stockholm, 27 - 31 May 2013, mimeo.

Domanico, F. (2007): Concentration in the European Electricity Industry: The Internal 
Market as Solution?, Energy Policy, 35(10), 5064-5076.

Downs, A. (1967): Inside Bureaucracy, Boston, MA, USA: Little, Brown and Company.

EAC (2012): Electricity Authoriy of Cyprus - Annual Report 2012, Nicosia.

EDF (2014): Shareholding Structure, available online: http://shareholders-and-investors.edf. com/edf-share/shareholding-structure-42691.html, April 2014.

Energiemyndigheten (2014): Mission, available online: http://www.energimyndigheten.se/ en/About-us/Mission, February 2014.

Energitilsynet (2014): The Danish Energy Regulatory Authority, available online: http:// energitilsynet.dk/tool-menu/english, February 2014.

Enveos (2014): Enovos International S.A. - Snapshot, available online: http://www.enovos.eu/ en/enovos-group/enovos-international-s.a/snapshot, April 2014.

ERSE (2013): Annual Report to the European Commission, August 2013, Lisbon.

ERSE (2014): ERSE, available online: http://www.erse.pt/eng/erse/Paginas/default.aspx, February 2014.

ERÚ (2014): The Energy Regulatory Office, available online: http://www.eru.cz/dias-read article.php?articleId=331, February 2014.

European Commission (2001): Communication from the Commission to the Council and the European Parliament - Completing the Internal Energy Market; Proposal for a Directive of the European Parliament and of the Council Amending Directives 96/92/EC and 98/30/EC Concerning Common Rules for the Internal Market in Electricity and Natural Gas (2001/0077 (COD)); Proposal for a Regulation of the European Parliament and of the Council on Conditions for Access to the Network for Cross-Border Exchanges in Electricity (2001/0078 (COD)), $\operatorname{COM}(2001) 125$ final, 13 March 2001, Brussels.

European Commission (2004): Note of DG Energy \& Transport on Directives 2003/54/EC and 2003/55/EC on the Internal Market in Electricity and Natural Gas - The Unbundling Regime, 16 January 2004, Brussels. 
European Commission (2005): Commission Decision of 13/06/2005 Initiating an Inquiry into the Gas and Electricity Sectors Pursuant to Article 17 of Council Regulation (EC) No 1/2003 - Cases COMP/B-1/39.172 (Electricity) and 39.173 (Gas), Brussels.

European Commission (2007a): Communication from the Commission - Inquiry Pursuant to Article 17 of Regulation (EC) No 1/2003 into the European Gas and Electricity Sectors (Final Report), COM(2006) 851 final, 10 January 2007, Brussels.

European Commission (2007b): DG Competition Report on Energy Sector Inquiry - 10 January 2007, SEC(2006) 1724, Brussels.

European Commission (2007c): Communication from the Commission to the Council and the European Parliament - Prospects for the Internal Gas and Electricity Market, COM(2006) 841 final, 10 January 2007, Brussels.

European Commission (2007d): Communication from the Commission to the European Council and the European Parliament - An Energy Policy for Europe, COM(2007) 1 final, 10 January 2007, Brussels.

European Commission (2012): Commission Decision of 14.5.2012 on the Application of Article 9(9) of Directive 2009/72/EC to Transmission System Operation in Scotland, C(2012) 3284 final, 14 May 2012, Brussels.

European Commission (2013a): Commission Decision of 12.4.2013 Pursuant to Article 3(1) of Regulation (EC) No 714/2009 and Article 10(6) of Directive 2009/72/EC - Ireland - Eirgrid/ESB, C(2013) 2169 final, 12 April 2013, Brussels.

European Commission (2013b): Commission Decision of 12.4.2013 Pursuant to Article 3(1) of Regulation (EC) No 714/2009 and Article 10(6) of Directive 2009/72/EC - United Kingdom (Northern Ireland) - SONI/NIE, C(2013) 2170 final, 12 April 2013, Brussels.

European Commission (2014a): Certification of TSOs - List of Notifications Received, available online: ec.europa.eu/energy/gas_electricity/interpretative_notes/doc/certification/2013 _received_notifications.xlsx, March 2014.

European Commission (2014b): Country report - Malta, available online: http:// 
ec.europa.eu/energy/gas_electricity/doc/mt_energy_market_2011_en.pdf, March 2014.

European Commission (2014c): Country report - Bulgaria, available online: http:// ec.europa.eu/energy/gas_electricity/doc/bg_energy_market_2011_en.pdf, March 2014.

European Commission (2014d): Country report - Cyprus, available online: http:// ec.europa.eu/energy/gas_electricity/doc/cy_energy_market_2011_en.pdf, March 2014.

European Commission (2014e): Country report - Luxembourg, available online: http:// ec.europa.eu/energy/gas_electricity/doc/lu_energy_market_2011_en.pdf, March 2014.

European Commission (2014f): Country report - Hungary, available online: http:// ec.europa.eu/energy/gas_electricity/doc/hu_energy_market_2011_en.pdf, March 2014.

European Communities (1996): Directive 96/92/EC of the European Parliament and of the Council of 19 December 1996 Concerning Common Rules for the Internal Market in Electricity, Official Journal of the European Communities L27, 30 January 1997, 20-29.

European Union (2003): Directive 2003/54/EC of the European Parliament and of the Council of 26 June 2003 Concerning Common Rules for the Internal Market in Electricity and Repealing Directive 96/92/EC, Official Journal of the European Union L176, 15 July 2003, 37-55.

European Union (2009): Directive 2009/72/EC of the European Parliament and of the Council of 13 July 2009 Concerning Common Rules for the Internal Market in Electricity and Repealing Directive 2003/54/EC, Official Journal of the European Union L211, 14 August 2009, 55-93.

Fudenberg, D. and Tirole, J. (1991): Game Theory, Cambridge, MA, USA and London, UK: MIT Press.

Geldhof, W. and Vandendriessche, F. (2008): European Electricity and Gas Market Liberalisation. Background, Status, Developments, in: Delvaux, B., Hunt, M. and Talus, K. (eds.): EU Energy Law and Policy Issues, ELRF Collection, 1st Edition, Rixensart, Belgium: Euroconfidentiel, 33-55.

Gilardi, F. (2008): Delegation in the Regulatory State - Independent Regulatory Agencies in Western Europe, Cheltenham, UK and Northampton, MA, USA: Edward Elgar. 
Höffler, F. and Kranz, S. (2011a): Legal Unbundling Can be a Golden Mean Between Vertical Integration and Ownership Separation, International Journal of Industrial Organization, $29(5), 576-588$.

Höffler, F. and Kranz, S. (2011b): Imperfect Legal Unbundling of Monopolistic Bottlenecks, Journal of Regulatory Economics, 39(3), 273-292.

Hondroyiannis, G. (2004): Estimating Residental Demand for Electricity in Greece, Energy Economics, 26(3), 319-334.

Jacobsen, D. I. (2006): Public Sector Growth: Comparing Politicians' and Administrators' Spending Preferences, Public Administration, 84(1), 185-204.

JARSE (2013): Report on the Energy Sector in Slovenia for 2012, 29 August 2013, Maribor.

JARSE (2014): About the Energy Agency - Introduction by the Director, available online: http://www.agen-rs.si/en/informacija.asp?id_meta_type=27\&id_informacija=634, February 2014.

Johannsen, K. S., Pedersen, L. H. and Sørensen, E. M. (2004): Independent Regulatory Authorities - A Comparative Study of European Energy Regulators, AKF Forlaget, April 2004.

Joskow, P. L. (2007): Regulation of Natural Monopoly, in: Polinsky, A. M. and Shavell, S. (eds.): Handbook of Law and Economics - Volume 2, Amsterdam, Netherlands et al.: NorthHolland, 1227-1348.

Karan, M. B. and Kazdağli, H. (2011): The Development of Energy Markets in Europe, in: Dorsman, A., Westerman, W., Karan, M. B. and Özgür, A. (eds.), Financial Aspects in Energy - A European Perspective, Berlin and Heidelberg, Germany: Springer, 11-32.

Kay, J. and Vickers, J. (1990): Regulatory Reform: An Appraisal, in: Majone, G. (ed.): Deregulation or Re-Regulation? - Regulatory Reform in Europe and the United States, London, GB: Pinter Publishers and New York, NY, USA: St. Martin's Press, 223-251.

Krueger, A. B. (1988): The Determinants of Queues for Federal Jobs, Industrial and Labor 
Relations Review, 41(4), 567-581.

Laffont, J. J. and Tirole, J. (1991): The Politics of Government Decision-Making: A Theory of Regulatory Capture, Quarterly Journal of Economics, 106(4), 1089-1127.

Lauth, T. P. (1986): The Executive Budget in Georgia, State and Local Government Review, $18(2), 56-64$.

LeLoup, L. T. and Moreland, W. B. (1978): Agency Strategies and Executive Review: The Hidden Politics of Budgeting, Public Administration Review, 38(3), 232-239.

Madlener, R., Bernstein, R. and Gonzlez, M. Á. A. (2011): Econometric Estimation of Energy Demand Elasticities, E.ON Energy Research Center Series, Volume 3, Issue 8, E.ON Energy Research Center, RWTH Aachen.

MEKH (2014): The Hungarian Energy and Public Utility Regulatory Authority, available online: http://www.mekh.hu/en/, February 2014.

Meyer, R. (2012): Vertical Economies and the Costs of Separating Electricity Supply - A Review of Theoretical and Empirical Literature, Energy Journal, 33(4), 161-185.

Migué, J.-L. and Bélanger, G. (1974): Toward a General Theory of Managerial Discretion, Public Choice, 17(1), 27-47.

MIT (2011): The Future of the Electricity Grid - An Interdisciplinary MIT Study, Massachusetts Institute of Technology, December 2011.

Mitnick, B. M. (1980): The Political Economy of Regulation - Creating, Designing, and Removing Regulatory Reforms, New York, NY, USA: Columbia University Press.

Mulder, M and Shestalova, V. (2006): Costs and Benefits of Vertical Separation of the Energy Distribution Industry: The Dutch Case, Competition and Regulation in Network Industries, 1(2), 197-230.

Moe, T. M. (1989): The Politics of Bureaucratic Structure, in: Chubb, J. E. and Peterson, P. E. (eds.), Can the Government Govern?, Washington, D.C., USA: Brookings Institution Press, 267-329. 
MVM (2014): The Mission of MVM, available online: http://www.mvm.hu/en/activities/ mission/Lapok/default.aspx, April 2014.

Narayan, P. K., Smyth, R. and Prasad, A. (2007): Electric Consumption in G7 Countries: A Panel Cointegration Analysis of Residental Demand Elasticities, Energy Policy, 35(9), 4485-4494.

Newbery, D. M. (1999): Privatization, Restructuring, and Regulation of Network Utilities, Cambridge, MA, USA and London, UK: MIT Press.

Niskanen, W. A. (1968): Nonmarket Decision Making - The Peculiar Economics of Bureaucracy, American Economic Review, 58(2), 293-305.

Niskanen, W. A. (1975): Bureaucrats and Politicians, Journal of Law and Economics, 18(3), 617-643.

Noll, R. G. (1989): Economic Perspectives on the Politics of Regulation, in: Schmalensee, R. and Willing, R. D. (eds.): Handbook of Industrial Organization, Volume II, Amsterdam; Netherlands et al.: North-Holland, 1253-1287.

OECD (2001): Restructuring Public Utilities for Competition, Paris, France: OECD Publishing.

OECD/IEA (2001): Regulatory Institutions in Liberalised Electricity Markets, Paris, France: IEA Publications.

Ofgem (2014): Working for Consumers, available online: https://www.ofgem.gov.uk/ about-us/how-we-work/working-consumers, February 2014.

Ogus, A. (2004): Regulation - Legal Form and Economic Theory, Re-issue, Oxford, UK and Portland, OR, USA: Hart Publishing.

Peters, B. G. (1978): The Politics of Bureaucracy - A Comparative Perspective, New York, NY, USA and London, UK: Longman.

Polemis, M. L. (2007): Modeling Industrial Energy Demand in Greece Using Cointegration 
Techniques, Energy Policy, 35(8), 4039-4050.

Pollitt, M. (2008): The Arguments for and Against Ownership Unbundling of Energy Transmission Networks, Energy Policy, 36(2), 704-713.

PPC (2014): Shareholders, available online: http://www.dei.gr/en/xrimatistiriaka-stoixeia/ metoxiki-sunthesi, April 2014.

RAE (2014): Activity Fields, available online: http://www.rae.gr/site/en_US/categories_new/ about_rae/domain.csp, February 2014.

Rourke, F. E. (1984): Bureaucracy, Politics, and Public Policy, 3rd Edition, Boston, MA, USA and Toronto, Canada: Little, Brown and Company.

Ryu, J. E., Bowling, C. J., Cho, C.-L. and Wright, D.S. (2007): Effects of Administrators' Aspirations, Political Principals' Priorities, and Interest Groups' Influence on State Agency Budget Requests, Public Budgeting \& Finance, 27(2), 22-49.

Sakhrani, V. and Parsons, J. E. (2010): Electricity Network Tariff Architectures - A Comparison of Four OECD Contries, Working Paper 10-008, Center for Energy and Environmental Policy Research, Massachusetts Institute of Technology, July 2010.

Salant, D. J. (1995): Behind the Revolving Door: A New View of Public Utility Regulation, Rand Journal of Economics, 26(3), 362-377.

Schneider, V. and Jäger, A. (2003): The Privatization of Infrastructures in the Theory of the State: An Empirical Overview and a Discussion of Competing Theoretical Explanations, in: Wubben, E. F. M. and Hulsink, W. (eds.), On Creating Competition and Strategic Restructuring - Regulatory Reform in Public Utilities, Cheltenham, UK and Northampton, MA, USA: Edward Elgar, 101-137.

Sharkansky, I. (1965): Four Agencies and an Appropriations Subcommitee: A Comparative Study of Budget Strategies, Midwest Journal of Political Science, 9(3), 254-281.

Sharkansky, I. (1968): Agency Requests, Gubernatorial Support and Budget Success in State Legislatures, American Political Science Review, 62(4), 1220-1231. 
Sherman, R. (2008): Market Regulation, Boston, MA, USA et al.: Pearson - Addison Wesley.

Sibley, D. S. and Weisman, D. L. (1998): Raising Rivals' Costs: The Entry of an Upstream Monopolist into Downstream Markets, Information Economics and Policy, 10(4), 451-470.

Sigelman, L. (1986): The Bureaucrat as Budget Maximizer: An Assumption Examined, Public Budgeting \& Finance, 6(1), 50-59.

Simon, C. P. and Blume, L. (1994): Mathematics for Economists, New York, NY, USA and London, UK: W. W. Norton \& Company.

Small, J. P. (1999): The Design of Economic Regulation for Utilities: A Primer, Center for Research in Network Economics and Communication, University of Auckland, August 1999.

Smith, W. (1997): Utility Regulators - The Independence Debate, Public Policy for the Private Sector, Note No. 127 (October), Washington, D.C.: The World Bank Group - Finance, Private Sector and Infrastructure Network.

Stigler, G. J. (1971): The Theory of Economic Regulation, Bell Journal of Economics and Management Science, 2(1), 3-21.

Thatcher, M. (2002a): Delegation to Independent Regulatory Agencies: Pressures, Functions and Contextual Mediation, West European Politics, 25(1), 125-147.

Thatcher, M. (2002b): Regulation After Delegation: Independent Regulatory Agencies in Europe, Journal of European Public Policy, 9(6), 954-972.

Thatcher, M. and Stone Sweet, A. (2002): Theory and Practice of Delegation to NonMajoritarian Institutions, West European Politics, 25(1), 1-22.

Thompson, J. A. (1987): Agency Requests, Gubernatorial Support and Budget Success in State Legislatures Revisited, Journal of Politics, 49(3), 756-779.

Train, K. E. (1991): Optimal Regulation - The Economic Theory of Natural Monopoly, Cambridge, MA, USA and London, UK: MIT Press.

Trebing, H. M. (1977): Broadening the Objectives of Public Utility Regulation, Land Eco- 
nomics, 53(1), 106-122.

Tullock, G., Seldon, A. and Brady, G. L. (2002): Government Failure - A Primer in Public Choice, Washington, D.C., USA: Cato Institute.

URE (2013): National Report - The President of the Energy Regulatory Office in Poland 2013, 4 September 2013, Warsaw.

URSO (2014): The Office, available online: http://www.urso.gov.sk/?q=the-office\&language $=$ en, February 2014 .

Varian, H. R. (2010): Intermediate Microeconomics - A Modern Approach, 8th Edition, New York, NY, USA and London, UK: W. W. Norton \& Company.

Venetoklis, T. and Kiander, J. (2006): Spending Preferences of Public Sector Officials: Survey Evidence from Finland, Public Budgeting \& Finance, 26(2), 20-44.

Wildavsky, A. and Caiden, N. (2004): The New Politics of the Budgetary Process, 5th Edition, New York, NY, USA et al.: Pearson Longman.

Wilks, S. and Bartle, I. (2002): The Unanticipated Consequences of Creating Independent Competition Agencies, West European Politics, 25(1), 148-172.

Zachariadis, T. and Pashourtidou, N. (2007): An Empirical Analysis of Electricity Consumption in Cyprus, Energy Economics, 29(2), 183-198. 